\title{
Experimental Study on the Stability of the Transmission Tower with Hybrid Slab
}

\section{Foundation}

\author{
Guanglin Yuan ${ }^{1}$, Biao Yang ${ }^{1}$, Zhaohui Huang ${ }^{2, *}$, Xiaozhe Tan ${ }^{1}$
}

1 State Key Laboratory for Geomechanics \& Deep Underground Engineering, School of Mechanics \& Civil Engineering, China University of Mining \& Technology, Xuzhou, Jiangsu 221116, China.

2 Department of Civil and Environmental Engineering, College of Engineering, Design and Physical Science, Brunel University, Uxbridge, Middlesex, UB8 3PH, U.K.

\begin{abstract}
In this paper, a 1:5 scaled tower model for a typical $220 \mathrm{kV}$ single-circuit power transmission tower with hybrid slab foundation has been designed and tested. The scaled tower model was tested under the movement of horizontal ground surface stretching with normal working loading conditions. One of the main objectives of this research is to investigate the stability of the power transmission tower subjected to horizontal ground movement by using hybrid slab foundation. The deformations of the tested tower model and stresses and strains within the different structural members of the tower and the reinforced concrete slab of the foundation have been fully measured. A large mount comprehensive test data has been generated. The research clearly indicated that compared to the isolated tower leg's foundation the proposed hybrid slab foundation has very good resistance, in terms of truss members' deformations and stresses, to the ground movement.
\end{abstract}

Keywords: Power transmission tower; hybrid slab foundation; ground movements; scaled tower model.

* Corresponding author, Email: zhaohui.huang@brunel.ac.uk 


\section{Highlights:}

Conduct a test on the 1:5 scaled tower model of $220 \mathrm{kV}$ power transmission tower with hybrid slab foundation;

Investigate the stability of the tower subjected to horizontal ground surface motion;

Generates a series of valuable test data on the behaviour of the tower;

Compare the behaviour of the scaled tower model with different type foundations. 


\section{Introduction}

In recent years, with increasing power demands, the safety of the power transmission line is vital important. Hence, the structural behaviour of transmission towers subjected to different loading and environmental conditions is an important research area which attracts many researchers [1-6]. In some countries, such as China, many transmission towers have to pass across coal mining areas, where ground surface cracking, subsidence, non-uniform settlement, etc. have caused partial or overall damage of many transmission towers [7-9]. The construction of ultra-high-voltage transmission systems requires even higher reliability of transmission towers.

Bruhn et al. [10] have studied the structural behaviour of lattice steel transmission tower under the ground surface's motion in the mining areas. Sun [11] proposed a composite reinforced concrete slab foundation to enhance the resistance of the transmission towers on the ground deformations. Li et al. [12] have analysed the structural responses of transmission towers under coupled actions between the tower and the transmission wires using FE method. Based on FE analysis, Yang et al. [13] suggested that the resistance of transmission towers on ground deformation could be increased considerably by using large scale flat-slab foundation. Shu et al. [14] have proposed a method for determining the thickness of the slab foundation based on a series of FE analyses. Yuan et al. [15] conducted an experimental test on a $500 \mathrm{kV}$ self-supporting transmission tower to study the structural behaviour of the tower subjected to the stretching and compressing of the tower's supports. Moon et al. [16] conducted an experiment on a half-scaled sub-structure of transmission tower to investigate the failure mode of the tower under wind load. Prasad Rao et al. [17-18] have carried out a series of full-scale tests on the transmission towers to study the early failure modes of the towers and the causes of failure. Also they have conducted a series of numerical analyses on the transmission towers using software NE-Nastran. The numerical results have been compared with the calculations from different design codes.

As mentioned above, the majority of the studies conducted on the behaviour of transmission tower subjected to ground deformations were mainly focused on FE numerical analysis. Very 
limited researches have been done to experimentally investigate the impact of ground surface deformations on the structural stability of transmission towers. Therefore, the main objectives of this research are:

- Conduct a large-scale test on a 1:5 scaled sub-structure tower model for a typical 220 $\mathrm{kV}$ transmission tower with hybrid slab foundation for the first time. The test simulates the horizontal motion of ground surface.

- Investigate the stability of the $220 \mathrm{kV}$ power transmission tower subjected to horizontal ground surface motion by adopting the newly proposed hybrid slab foundation. The test generates a series of valuable data on the behaviour of the tower, stress and strain states within the structural members and foundation of the tower. The test data can be used to validate numerical models developed by the follow research in the field.

- Compare the behaviour of the scaled tower model with different type foundations of the transmission tower, and assess the tower's resistance to the ground movements by employing hybrid slab foundation.

\section{Design of Experiment}

The influences of the ground surface deformations, such as the ground surface level movement, horizontal tensile and compression deformations, and the tilting, etc., on the behaviour of the transmission tower in mining area are very complex. To design a large-scale test on the transmission tower which can consider the influence of tensile force of the conductors and ground-wire subjected to ground motion is very complicate and difficult. Due to the limitation of current structural lab's conditions in this research only self-weights of the tower and conductors and ground-wire were considered. Therefore the shift in tower center of gravity due to horizontal ground movement was negligible under only vertical loading conditions. This has been proved by previous test [19]. The more feasible way to investigate the behaviour of transmission tower under real loading conditions is to use FE analysis which needs to be validated under more simple loading conditions by using available test data.

Therefore, in this research a typical 1:5 scale tower model, which represent the bottom part of a real $220 \mathrm{kV}$ power transmission tower, was tested. The self-weights of the upper structure 
components including the conductors and ground-wire were considered. All loads were applied to the corresponding nodes on the top of the test tower model. Hence, the influence of tensile forces within the conductor and ground wire were ignored in the test.

\subsection{Test-rig for generating ground motion}

Based on the current laboratory conditions it is very difficult and complex to simulate a real ground movement for a full scaled original tower. Previous research [19] indicated that most significant impact on the behaviour of the tower is the ground horizontal movement. Hence, this research focused on this kind of ground movement conditions. Other ground movement conditions will be investigated in next phase of research by using FE modelling.

Fig. 1 shows a large-scale test rig which has been specially designed and constructed for simulating the horizontal motion of the ground surface. As shown in Fig. 1a, the test rig consists of two parts, a fixed box (bolted to the strong ground floor) and a movable box (equipped with rollers on the bottom). Two jacks were installed with reaction frame at two sides of the movable box which propel the movable box apart from the fixed box for simulating the horizontal ground motion.

\subsection{Design of the scaled tower model}

The prototype of the scaled tower model is a typical $220 \mathrm{kV}$ power transmission tower. As shown in Fig. 2, the overall height of the tower is $46.3 \mathrm{~m}$, the nominal height is $38 \mathrm{~m}$. The dimensions of the tower at the support level for both along and perpendicular to the power line direction are both $7.845 \mathrm{~m}$.

Considering the structural lab's test conditions, only the lower part of the tower (within the rectangular dash line, as shown in Fig. 2) was selected as the prototype of the scaled tower model. In order to represent the stiffness provided by the upper part of the whole tower structure to the scaled tower model, the additional horizontal diaphragms were added to the scaled tower model. Based on a series FE analyses by using the finite element software ANSYS for both real tower and scaled tower model, It was reasonable to select the steel bar member with the cross-section of L18 x 1.4 on the top of scaled tower model as additional diaphragms to simulate the stiffness provided by the upper part of the tower which was not included in the tested tower. The mass of the upper part of the original tower was considered in the test loading condition. 
In order to design scaled tower model, the same steel material of the real tower was used for the scale tower model. So the design of the scale tower model was based on the geometric shrinkage ratio. The scaled tower model was reduced to 1:5 compared to the real tower. Hence, the cross-section area of steel bar members of the scale tower model was $1 / 25$ of the original one. For calculating the loads applied to the scale tower model it is assumed that the axial stress of the steel bar members was the same compared to the real tower. As a result, the slenderness ratios of the steel bar members for the scaled tower model was the same as the original tower. This was validated by FE analyses for both scaled and real tower model.

In the actual engineering design, it is always to adopt the principle of strong joint with weak structural member to prevent the failure of joint before the failure of the members. Hence, in order to prevent the joints' failure in this experiment, 8.8 high strength bolt was used to replace 5.6 ordinary bolt of original tower. The details of the scaled tower model are shown in Fig. 3.

The legs of the scaled tower model were made of hot-rolled equal angle steel. Other truss members were made of cold worked angle steel. Table 1 lists the cross sectional properties of the whole tower and the scaled tower model. In order to avoid shear failure of the bolts, the high strength bolts M3 and M4 of Grade 8.8 were used. The tightening moments were 0.6 $\mathrm{N} \cdot \mathrm{m}$ for $\mathrm{M} 3$ and $2.0 \mathrm{~N} \cdot \mathrm{m}$ for $\mathrm{M} 4$, respectively. The scaled tower model was fabricated by the State Grid Jiangsu Huadian Steel Tower Manufacturing Co. Ltd.

\subsection{Validation of the scaled tower model}

In order to make sure that the scaled tower model can reasonably represent the behaviour of the whole tower subjected to the horizontal ground movements, both the whole tower and scaled tower model were modelled using ANSYS, respectively. The comparisons of deformations for the whole tower and scaled tower model under horizontal stretching of the supports, along the direction perpendicular to the power line, are presented in Figs. 4a and 4b. In the figure the different colours in the horizontal legend represent the magnitudes of axial stresses within the structural members. It is evident that the deformations in both cases are agreed reasonably well.

Based on the similarity law, the results obtained from the modelling of the scaled tower model can be converted into the data which can be used to compare with the results obtained 
from the modelling of the whole tower. Fig. 5 shows the comparison of the predicted forces in different members (see Fig. 11 for the members' positions) between the whole tower and scaled tower model. It can be seen that the axial forces in the tower's legs, horizontal diaphragms, diagonal trusses are reasonable agreed each other. However the axial forces in the cross bracing members (AX1 and AX3) have some discrepancies, especially at support displacement around $600 \mathrm{~mm}$. This is mainly due to the size of the tower legs' member was not exactly reduced to $1 / 5$ of real tower leg's member. The support's reaction forces differ at initial stage, but have the same trend. The possible reason to explain it is that the loads applied on the whole tower were more evenly distributed, compared to scaled test tower model in which the concentrated loads were applied. However, in the later stage, the stretching of the supports becomes dominant, leading to similar force-displacement curve.

Based on the validations presented above it can be concluded that the scaled tower model used can reasonably represent the behaviour of the whole tower. The boundary conditions designed in the test can reasonably simulate the real situation.

\subsection{Design of hybrid slab foundation for the scaled tower model}

The slab foundation for real whole tower was designed according to Chinese code. In Chinese code the main design criteria for slab foundation is the minimum reinforcement ratio. Hence, the reinforcement ratio of the scaled slab foundation was designed to be above the code requirement. The prototype of the hybrid slab foundation is an integrated reinforced concrete slab casted in-situ under the bottom of four isolated tower leg's foundations. The size of the slab is $11645 \mathrm{~mm}$ by $11645 \mathrm{~mm}$ (with a $4045 \mathrm{~mm}$ by $4045 \mathrm{~mm}$ opening at the middle). The slab is $400 \mathrm{~mm}$ thick. A $100 \mathrm{~mm}$ thick pebble and sand bedding is paved as a slip layer between the concrete slab and each of the isolated tower leg's foundations.

The same concrete and steel reinforcement materials were used for the foundation of the scaled tower model. As shown in Fig. 6a, the size of the foundation for the scaled tower model was reduced to 1:5. The size of the scaled hybrid slab foundation model was $2321 \mathrm{~mm}$ by $2321 \mathrm{~mm}$, with a $801 \mathrm{~mm}$ by $801 \mathrm{~mm}$ opening at the centre and the slab's thickness of 80 $\mathrm{mm}$. The size of the slip layer for each isolated tower leg's foundation (called isolated 
foundation in the rest of the paper) is $600 \mathrm{~mm} \times 600 \mathrm{~mm}$ with $20 \mathrm{~mm}$ thickness and material of medium size sand. The reinforcement used in the RC slab was determined based on the same reinforcement ratio compared to the original foundation. Hence, $\varnothing 6$ steel bar with the bar spacing of $250 \mathrm{~mm}$ was used. The yield strength and the ultimate strength of the reinforcement are 339.2 $\mathrm{MPa}$ and $482.1 \mathrm{MPa}$, respectively. The slab and the isolated foundations were casted using grade C20 concrete, in which the 28 day cubic compressive strength is $23.7 \mathrm{MPa}$. The details of the isolated foundation are showed in Fig. 6b.

\subsection{Fabrication of the hybrid slab foundation model}

For this test, only the horizontal ground movement was considered. The impact of the ground vertical movement was not investigated. To avoid the moving of the ground boxes during the filling of soil, the fixed box and the movable box were tied together via bolts (see Fig. 1a). There were two steps for the soil filling process. The first step was to fill and compact the soil up to $600 \mathrm{~mm}$ thick as the bottom part, which was done by filling $200 \mathrm{~mm}$ thick and then compacting to $150 \mathrm{~mm}$ thick layer by layer. The compactness coefficient was 0.91 . The measured compact soil properties are as follows:

Cohesive strength: $33 \mathrm{kPa}$;

Angle of internal friction: $17^{\circ}$;

Moisture content (by weight): 23.2\%;

Density: $1960 \mathrm{~kg} / \mathrm{m}^{3}$

After the bottom part was ready, $10 \mathrm{~mm}$ thick bedding cushion using M15 cement mortar was paved on the top, then the RC slab was casted on the top of them. When the RC slab was harden, the $20 \mathrm{~mm}$ thick slip layer was paved around the positions of four isolated foundations. After that four isolated reinforced concrete foundations were casted on the top of the slip layer.

Before constructing the isolated $\mathrm{RC}$ foundations, the positions of the four isolated foundations were located first. Then colligating steel bars, and burying transmission tower anchor bolts, putting formworks, pouring concrete were carried out. After 7 days' basic 
maintenance the formworks were dismantled (see Fig. 7).

For connecting the scaled tower onto the foundation, the bottom of the scaled tower legs was welded on the tower foot boots plates which were bolted with the bolts embedded in the foundation. The joints of the steel truss members of the tower were bolted using $8.8 \mathrm{M} 3$ and M4 high strength bolt. After 4 isolated RC foundations were completed, the upper layer soil was filled into the ground boxes. In order to prevent the difficulty for the installation of the scaled tower model on the isolated foundations, the scaled tower model was lifted to the right positions and fixed with the tower anchor bolts before casting concrete. The completed test setup is showed in Fig. 8.

\subsection{Material properties of the scaled tower model}

The tested material properties of the angle steel used for the scaled tower model are given in Table 2.

\section{Loading and Measuring}

\subsection{Loading scheme}

Under real working condition, the imposed loads acting on the transmission tower are wind, ice and earthquake. And the dead loads are self-weights of wire and the tower itself. Normally, the tower is working under the condition of $15{ }^{\circ} \mathrm{C}$ with no wind and no ice, which is the condition assumed in this study. The design loads used are given in Table 3, which are based on the recommendations from the handbook of "Typical Designs of Transmission and Transformation Engineering of State Grid - 220 kV Transmission Line”. The actual vertical loads on the scaled tower model were calculated according to the loads of the prototype of whole tower multiplied by a constant determined using the similar law.

Vertical loads were applied using equivalent weights hanging at the four top corners of the scaled tower model. The vertical load at each corner was $160 \mathrm{~kg}$. As shown in Fig. 1, the Jacks were mounted onto fixed box and used to push the moveable box horizontally moving apart from the fixed box (in the direction perpendicular to the power line). The displacement loading was applied step by step to simulate the horizontal ground surface movements. For each loading step $1 \mathrm{~mm}$ displacement was applied. 


\subsection{Measuring scheme}

In order to assess the stresses within the foundation RC slab, strain gauges were used to measure the strains within the steel reinforcing bars (see Fig. 9) and on the surface of the slab (see Fig. 10). Also strain gauges were used to measure the strains in the truss members of the scaled tower model. The arrangement of the strain gauges is illustrated in Fig. 11. The black filled dots along the tower's legs (see Fig. 11) mean that there are three strains gauges fixed at that position. Two of them fixed at each external surface of the angle member, and another one fixed at one internal surface of the angle member. All three strains gauges were orientated in the axial direction of the angle member for measuring the axial force and bending moment in the tower's legs. For the partial black filled dots, they represent only two strain gauges are used. They were attached at each external surface of the angle member and orientated in the axial direction of the angle member for measuring the axial force. For the no black filled dots, they mean only one strain gauge is used, which was attached at one external surface of the angle members and orientated in the axial direction of the angle members for measuring the axial force.

Three YHD-200 displacement meters were arranged on the each top surface of the isolated foundations to record vertical and horizontal (along and normal to the power line direction) displacements. Four YHD-200 displacement meters were mounted on the movable box to monitor each displacement loading step. Two DH801-750 guyed displacement meters were used to measure the horizontal displacements at the top of the scaled tower model in the directions along and perpendicular to the power line.

\section{Test Procedure and Observations}

\subsection{Test procedure}

The test was carried out in the structural lab at China University of Mining \& Technology (CUMT). The testing procedure is as follows:

(1) Setting up the scaled tower model on the test platform, calibrating the elevation of each supports;

(2) Mounting jacks, strain gauges, displacement meters and data acquisition equipment; 
(3) Packing the steel loading blocks on the loading platform which applied the vertical loads on the four top corners of the scaled tower model until the normal working loading condition was reached.

(4) Loosening the fixing and tying bolts of the movable box;

(5) Using jacks to apply the stretching horizontal displacement loads on the movable box with $1 \mathrm{~mm}$ loading step. After the relevant data readings became stable in each loading step, then started next loading step. The displacement load was increased step by step until the maximum displacement of $50 \mathrm{~mm}$ was reached or the deformations of the truss members within the scaled test tower model became negligible.

(6) All measured parameters were recorded step by step by the computer via the data collection devices.

Fig. 12 shows the elevation of the integrated test setup and the panorama view of the test is shown in Fig. 13.

\subsection{Test observations}

Fig. 14 shows the cracking pattern of the foundation soil at the end of the test. The initiation and propagation of the cracks within the foundation soil during the test can be described as the following:

In the test, jacks were used to apply the stretching horizontal displacement on the movable box with $1 \mathrm{~mm}$ loading step (called loading displacement in the rest of the paper). With referencing to Fig. 14b, when the loading displacement reached to $6 \mathrm{~mm}$, a $4 \mathrm{~mm}$ wide crack (1) was seen in the soil along the edge of the isolated foundation $\mathrm{C}$. This crack propagated from the foundation $\mathrm{C}$ to the edge of the box, separating the foundation $\mathrm{C}$ from the soil. With the further loading the width of the crack (1) was increased, also a $4 \mathrm{~mm}$ wide crack (2) appeared in the soil along the edge of the isolated foundation B. The crack propagated from the foundation $\mathrm{B}$ to the edge of the box. With the further loading the opening width of the cracks increased.

When the loading displacement reached to $8 \mathrm{~mm}$, the isolated foundation B was separated from the soil and a new $5 \mathrm{~mm}$ wide crack (3) formed. The opening of the crack increased 
with the displacement. With a further loading, a $3 \mathrm{~mm}$ wide crack (4) appeared near the isolated foundation $\mathrm{A}$, but the opening of the crack did not increase with the subsequent loading.

When the loading displacement reached to $11 \mathrm{~mm}$, near the juncture of the two boxes, adjacent to the jack 2, a $3 \mathrm{~mm}$ wide diagonal crack (5) formed. With the further loading the opening of the crack was widened and the crack propagated towards the isolated foundation C. Meanwhile, the crack (3) propagated towards foundation C, and a crack (6) was formed and propagated towards the isolated foundation B. The openings of cracks (3) and (6) were increased with the further loading. When the loading displacement reached to $15 \mathrm{~mm}$, the crack (5) reached to the isolated foundation C.

When the loading displacement reached to $14 \mathrm{~mm}$, a tiny crack (7) appeared between the isolated supports $\mathrm{A}$ and $\mathrm{B}$ and the crack (6) near the isolated support $\mathrm{C}$ propagated diagonally. When the loading displacement reached to $17 \mathrm{~mm}$, the crack (3) near the isolated support B diverted diagonally. When the loading displacement reached to $19 \mathrm{~mm}$, a new diagonal crack (8) formed and joined with the crack (6). When the loading displacement reached to $24 \mathrm{~mm}$, a diagonal crack (9) near the isolated support B formed and merged with the crack (3). When the loading displacement reached to $31 \mathrm{~mm}$ the cracks (8) and (9) between the isolated supports B and C merged. After this point, no new cracks formed with further loading but the openings of the cracks between the isolated supports B and C were increased.

It was observed that there were very little deformations of all members of the scaled tower model above the isolated foundations during the test. The relative movements of the isolated foundations were very small. The damage pattern of the soil at the foundation after test is shown in Fig. 14. It can be seen from Figs. 14a and 14b that the cracks are along the edges of the isolated foundations. From Figs. $14 \mathrm{c}$ and $14 \mathrm{~d}$, it is clear that the cracking of soil started along the juncture between the two boxes. However, due to the foundation RC slab under the four isolated foundations, the crack could not propagate upwards through the RC slab, but to propagate along the edge of the slab. The cracking underneath the RC slab basically follows the pattern showed in Fig. 14c. After the test, the overlying soil was removed from the foundation RC slab for observation. There were no any cracks found in the foundation RC slab. This suggests that under the ground horizontal deformation, the foundation RC slab 
significantly reduced the impacts of ground movement on the isolated four independent foundations of the tower.

\section{Analysis of Test Results}

\subsection{Horizontal displacements of the scaled tower's supports}

Fig. 15 shows the horizontal displacements of the scaled tower's supports along loading displacement direction. It can be seen that the maximum displacement of the supports was less than $2.5 \mathrm{~mm}$. This indicates that the foundation $\mathrm{RC}$ slab which was underneath of the isolated foundations can effectively minimize the influence of deformation of the ground on the supports of the scaled tower model. When the loading displacement was beyond $10 \mathrm{~mm}$, the displacements of the supports B and $\mathrm{C}$ were almost no change. For the supports $\mathrm{A}$ and $\mathrm{D}$, their displacements were decreased after the loading displacement was greater than $8 \mathrm{~mm}$. This is due to the cracking happened within the soil around the isolated foundations. Hence, the influence of the foundation soil on the isolated foundations became weaker and weaker. Consequently, the impact of the ground movement on the supports of the scaled tower was very limited due to the hybrid slab foundation used in this study.

The reason for the displacements of the supports $\mathrm{A}$ and D reduced after the loading displacement was greater than $8 \mathrm{~mm}$ is due to the soil in the fixed box sprang back after cracking formed near the juncture of the two boxes (see Fig. 14d) which dragged the supports A and D backward. When the loading displacement reached beyond $15 \mathrm{~mm}$, the displacements of the supports $\mathrm{A}$ and $\mathrm{D}$ stabilized at $0.25 \mathrm{~mm}$ and the displacements of the supports B and C stabilized at $2.2 \mathrm{~mm}$, respectively. This means that the further displacement loading has little influence on the supports of the scaled tower model and the tower structures above the supports. Therefore, the use of hybrid slab foundation proposed in this research can effectively minimize the effect of the ground movements on the structural behaviour and stability of the transmission tower.

\subsection{Subsiding at supports and horizontal displacement at the top of the scaled tower model}

Fig.16 shows the vertical subsidence of the supports against the loading displacement. It can be seen that the vertical displacements of the supports B and C are very similar with the 
maximum displacement of $2.4 \mathrm{~mm}$. The vertical displacements of the supports A and D are almost same with the maximum displacement of $0.35 \mathrm{~mm}$. The difference between supports A-D and B-C indicates the non-uniform subsidence of the supports. This was mainly caused by the cracking of foundation soil. However, overall the vertical subsidence of the supports was very small and the influence on the structural behaviour of the scaled tower model should be negligible.

Fig. 17 shows the horizontal displacements along the direction of the loading displacement at four top corners of the scaled tower model. It can be seen that maximum displacements of 5.5 $\mathrm{mm}$ and $5.0 \mathrm{~mm}$ appeared at the tops of the tower's legs 1 and 2 and the tower's legs 3 and 4, respectively. The difference of the horizontal displacements between the top and the supports of the scaled tower model was mainly due to the non-uniform vertical subsidence of the supports. The test results indicated that there were no obvious deformations happened within the members of the scaled tower model. Hence, the impact of horizontal ground motions on the scaled tower model with hybrid slab foundation proposed in this research is insignificant.

\subsection{Stresses in the RC slab}

Due to the interaction between the foundation RC slab and soil, the stresses developed within the RC slab were caused by the loading displacement. Fig. 18 shows the tensile stresses developed in the reinforcing steel bars along the loading displacement direction at the positions of SB-2-3 (top layer) and XB-2-3 (bottom layer) which was $1155 \mathrm{~mm}$ away from the edge of the RC slab within the fixed box (see Fig. 9). The maximum tensile stresses were about $120 \mathrm{MPa}$ at the bottom layer, and $100 \mathrm{MPa}$ at the top layer, respectively.

Fig. 19 shows the compressive stresses developed in the reinforcing steel bars normal to the loading displacement direction at the positions of SB-2-2 (top layer) and XB-2-2 (bottom layer) which was $385 \mathrm{~mm}$ away from the edge of the RC slab within the fixed box (see Fig. 9). The maximum compressive stresses were about $74 \mathrm{MPa}$ at the top layer, and $35 \mathrm{MPa}$ at the bottom layer, respectively.

From Figs. 18 and 19 it can be seen that the stresses of top and bottom layers were changed considerably different at the loading displacement of $25 \mathrm{~mm}$. This is due to a major crack 
formed under the RC slab at the positions of the strain gages (see Fig. 14). This resulted the loading condition on the RC slab changed and the RC slab was subjected to certain degree of bending at the positions of the strain gages.

It is evident that the stresses in the reinforcing steel bars were all well below the yield strength. This confirms that reinforcement ratio used for the foundation $\mathrm{RC}$ slab is adequate and the slab has had enough strength for resisting the ground motions.

\section{Comparison of Resistances to Ground Deformation for Two Type Foundations}

Yuan et al. [19] have conducted a test on the transmission tower with isolated leg's foundation subjected to ground movements. In order to assess the ground deformation resistance for different type foundations the results generated from that research are used to compare the test data obtained from this research. Fig. 20 shows the comparison of failure mode of the scaled tower model with isolated foundations against the maximum deformed profile of the scaled tower with hybrid slab foundation. It can be seen from Fig. 20(b) that the deformations of the scaled tower with hybrid slab foundation were small.

\subsection{Support's displacements}

According to the test results presented by Yuan et al. [19] and current research the displacements of the supports $\mathrm{A}$ and $\mathrm{D}$ within the fixed box are very small and can be neglected. Therefore, here only the displacements of the supports B and C within the movable box are considered for the comparison (see Fig. 1b and Fig. 11e for the positions).

Fig. 21 shows the horizontal displacement of the supports $\mathrm{B}$ and $\mathrm{C}$ with different type foundations against the loading displacement. It can be seen that the displacements of the supports $\mathrm{B}$ and $\mathrm{C}$ with the hybrid slab foundation used in this research are about $2 \mathrm{~mm}$. However, the displacements of the supports $\mathrm{B}$ and $\mathrm{C}$ with the isolated foundation used by Yuan et al. [19] are linearly increased with the loading displacement. It can be seen that for the case with isolated foundation the displacements of the supports B and C are almost to equal the loading displacement. This indicates that the isolated foundation has very little resistance to ground deformation. For the hybrid slab foundation used in this research the maximum displacements of the supports $\mathrm{B}$ and $\mathrm{C}$ were less than $2.0 \mathrm{~mm}$. Hence, the hybrid 
slab foundation proposed in this research has very good resistance to the ground movement and the impact due to the ground movement on the structural behaviour of the transmission tower can be significantly reduced.

\subsection{Stresses within the structural members of the scaled tower model}

The comparison of the axial stresses within the scaled tower model's legs at the positions L14, L24, L34 and L44 (see Fig. 11 for the locations) for the two type foundations is shown in Fig. 22. It can be seen that for the case with isolated foundation the axial stresses of the tower's legs increase linearly with the loading displacement. When the loading displacement reached to $50 \mathrm{~mm}$ the maximum stress was around $290 \mathrm{MPa}$. In contrast, the case with the hybrid slab foundation, very little stresses within the tower's legs were generated by the loading displacement.

Fig. 23 shows the axial stresses of the first cross bracing members AX1 and CX1 (see Fig. 11 for the members' positions) against the loading displacement for the two type foundations. Again the magnitude of the stresses in the members AX1 and CX1 for the isolated foundation is significantly greater than the one with the hybrid slab foundation.

The results presented above further confirm that the hybrid slab foundation proposed in this research has superior capability to insulate the impact of the ground movement on the structure of the tower above the supports. However, the isolated foundation has very little resistance to the ground movement. Therefore the impact of the ground movement on the tower structures above the supports is very significant if the isolated foundation is employed.

\section{Conclusions}

It is well known that the influences of the ground surface deformations on the behaviour of the transmission tower in mining area are very complex. At present the majority of the studies conducted for investigating the behaviour of transmission tower subjected to ground deformations were mainly focused on FE numerical analysis. Very limited researches have been done to experimentally investigate the impact of ground surface deformations on the structural stability of the transmission towers. In this paper a 1:5 scaled tower model for a typical $220 \mathrm{kV}$ single-circuit self-supporting transmission tower with hybrid slab foundation 
was designed and fabricated. The scaled tower model was tested subjected to the horizontal ground surface movements under the only gravity loading condition. The research first time to experimentally investigate the influence of different tower leg's foundation on the resistance of horizontal ground motion. The research generated valuable test data which can be used for the validation of FE numerical models. Then the validated FE models will be adopted to analyse the real transmission towers subjected to ground motion under more complex loading condition. The validation of developed FE model and a series of comprehensive parametric studies by using the validated FE model on the behaviours of the transmission tower under different ground movements and foundations will be published in another paper. Compared to the isolated tower leg's foundation the proposed hybrid slab foundation has very good resistance to the ground movement. The impact of ground movements on the tower structures above the supports can be significantly reduced by using this kind of foundation. It is therefore suggested that the hybrid slab foundation proposed in this research can be used for the transmission tower in the mining areas with significant ground deformations.

\section{Acknowledgement}

This research was supported by the science and technology projects of China's State Grid Company (Grant No. SGSXYQ00XTJS-(2015)-215). The authors gratefully appreciate this support.

\section{References}

1. Battista RC, Rodrigues RS, Pfeil MS. Dynamic behavior and stability of transmission line towers under wind forces. Journal of Wind Engineering and Industrial Aerodynamics 2003; 91: 1051-1067.

2. Kudzys A. Safety of power transmission line structures under wind and ice storms. Engineering Structures 2006; 28: 682-689.

3. Savory E, Parke GAR, Disney P, Toy N. Wind-induced transmission tower foundation loads: A field study-design code comparison, Journal of Wind Engineering and Industrial Aerodynamics 2008; 96: 1103-1110.

4. Albermani F, Kitipornchai S, Chan RWK. Failure analysis of transmission towers. Engineering Failure Analysis 2009; 16: 1922-1928.

5. Hamada A, El Damatty AA. Behaviour of guyed transmission line structures under tornado wind loading. Computers and Structures 2011; 89: 986-1003. 
6. Kyung D, Choi Y, Jeong S, Lee J. Improved performance of electrical transmission tower structure using connected foundation in soft ground. Energies 2015; 8: 4963-4982.

7. Zhenhua S. Settlement and the treatment plan for the foundation of the tangent towers of the transmission lines in the goaf of coal mine. Shanxi Power Technology 1997; 17: 18-20.

8. Yang F, Yang J, Han J. Study on the limited values of foundation deformation for a typical UHV transmission tower. IEEE Transactions on Power Delivery 2010; 25(4): 2752-2758.

9. Jia L, Zai H. Design and Operation of Power Line in Mining Area (Beijing: China Electric Power Press 2015.

10. Bruhn RW, Ferrell JR, Luxbacher GW. The structural response of a steel-lattice transmission tower to mining related ground movements. Proceedings of the 10th International Conference on Ground Control in Mining, West Virginia University, Morgantown WV, 1991; 301-306.

11. Sun JH. Experience and measure for design the transmission line in empty coal mine. Shan Xi Electric Power 2004; 3: 13-14.

12. Li B, Jian M, Zhang D. Finite element analysis of foundation settlement of $220 \mathrm{kv}$ transmission tower with independent foundation. Applied Mechanics and Materials 2012; 201-202: 602-607.

13. Yang F, Li Q, Yang J, Zhu B, Assessment on the stress state and the maintenance schemes of the transmission tower above goaf of coal mind. Engineering Failure Analysis 2013; 31: 236-247.

14. Shu QJ, Yuan GL, Guo GL, Zhang YF. Research on the composite foundation anti-deformation performance and optimal thickness of electricity transmission towers in mining subsidence area. Journal of Disaster Prevention and Mitigation Engineering, 2012; 32( 3): 294-298.

15. Yuan GL, Zhang F., Li S, Liu T, Ji Y. Model experiment on anti-deformation performance of self-supporting transmission tower in subsidence area. International Journal of Mining Science and Technology 2012; 22(1): 57-62.

16. Moon BW, Park JH, Lee SK, Kim J, Kim T, Min KW. Performance evaluation of a transmission tower by substructure test. Journal of Constructional Steel Research 2009; 65: 1-11.

17. Prasad Rao N, Samuel Knight GM, Seetharaman S, Lakshmanan N, Iyer NR, Failure analysis of transmission line towers. Journal of Performance of Constructed Facilities 2011; 25: 231-240.

18. Prasad Rao N, Samuel Knight GM, Mohan SJ, Lakshmanan N. Studies on failure of transmission line towers in testing. Engineering Structures 2012; 35: 55-70.

19. Shu QJ, Yuan GL, Huang ZH, Ye S. The behaviour of the power transmission tower subjected to horizontal support's movements. Engineering Structures, 2016;123:166-180. 


\section{List of Tables and Figures}

Table 1 The sectional properties of the members for the whole tower and scaled tower model.

Table 2 Measured yield strength of angle steel (MPa).

Table 3 Wire loads under normal working condition.

Fig. 1 Test rig for simulating horizontal ground movements.

Fig. 2 The prototype of the $220 \mathrm{kV}$ transmission tower used (all dimensions in $\mathrm{mm}$ ).

Fig. 3 Details of the 1:5 scaled tower model (all dimensions in $\mathrm{mm}$ ).

Fig. 4 Deformed diagrams of: (a) the sub-structure of whole tower analysed; (b) the scaled tower model (magnified by 5 times).

Fig. 5 Comparison of the predicted forces against the support's displacements between the whole tower and scaled test tower model.

Fig. 6 Details of the proposed hybrid slab foundation model (all dimensions in $\mathrm{mm}$ ).

Fig.7 Completed hybrid slab foundation.

Fig. 8 The completed test setup.

Fig. 9 Arrangement of strain gauges attached to the reinforcing steel bars in the foundation RC slab (SB-top layer; XB-bottom layer).

Fig. 10 Arrangement of strain gauges on the surface of the foundation RC slab.

Fig. 11 Strain gauges arrangement and member's labels on the scaled tower model.

Fig. 12 Elevation of the integrated test setup.

Fig. 13 Panorama view of the test.

Fig. 14 Cracking pattern within the foundation soil.

Fig. 15 Horizontal support's displacement against loading displacement.

Fig. 16 Vertical subsidence of the supports against loading displacement.

Fig. 17 Horizontal displacements at the top corners of the scaled tower model against loading displacement.

Fig. 18 Stresses within the reinforcing steel bars against loading displacement.

Fig. 19 Stresses within the reinforcing steel bars against loading displacement.

Fig. 20 Comparison of failure mode of the scaled tower model with isolated foundations against the maximum deformed profile of the scaled tower with hybrid slab foundation.

Fig. 21 The horizontal displacements of the supports with different foundations.

Fig. 22 Stresses within the tower legs' members with different type foundations (IF = isolated foundation; HSF = hybrid slab foundation).

Fig. 23 The stresses in the first cross bracing members with different type foundations (IF $=$ isolated foundation; HSF $=$ hybrid slab foundation). 


\section{List of Tables}

Table 1 The sectional properties of the members for the whole tower and scaled tower model.

\begin{tabular}{|c|c|c|c|c|c|}
\hline \multirow{2}{*}{$\begin{array}{c}\text { Member } \\
\text { classification }\end{array}$} & \multirow[b]{2}{*}{ Steel } & \multicolumn{2}{|c|}{ Whole tower } & \multicolumn{2}{|c|}{ Scaled tower model } \\
\hline & & $\begin{array}{l}\text { Section size } \\
(\mathrm{mm} \times \mathrm{mm})\end{array}$ & $\begin{array}{c}\text { Section area } \\
\left(\mathrm{mm}^{2}\right)\end{array}$ & Section size $(m m \times m m)$ & $\begin{array}{c}\text { Section area } \\
\left(\mathrm{mm}^{2}\right)\end{array}$ \\
\hline Tower's leg & Q345 & $\mathrm{L} 140 \times 10$ & 2737 & $\mathrm{~L} 25 \times 3$ & 143 \\
\hline $\begin{array}{l}\text { Horizontal } \\
\text { diaphragm }\end{array}$ & Q235 & L90 $\times 7$ & 1230 & $\mathrm{~L} 18 \times 1.5$ & 54 \\
\hline \multirow{3}{*}{ Bracing } & \multirow{3}{*}{ Q235 } & $\mathrm{L} 75 \times 5$ & 741 & $\mathrm{~L} 15 \times 1$ & 30 \\
\hline & & $\mathrm{L} 70 \times 5$ & 688 & $\mathrm{~L} 14 \times 1$ & 28 \\
\hline & & $\mathrm{L} 63 \times 5$ & 614 & $\mathrm{~L} 13 \times 1$ & 26 \\
\hline \multirow{3}{*}{$\begin{array}{l}\text { Auxilliary } \\
\text { member }\end{array}$} & \multirow{3}{*}{ Q235 } & $\mathrm{L} 45 \times 4$ & 349 & $\mathrm{~L} 9 \times 0.8$ & 14.4 \\
\hline & & $\mathrm{L} 40 \times 4$ & 309 & $\mathrm{~L} 8 \times 0.8$ & 12.8 \\
\hline & & $\mathrm{L} 40 \times 3$ & 236 & $\mathrm{~L} 8 \times 0.8$ & 12.8 \\
\hline
\end{tabular}

Note: The angle of L140x10 is hot rolled, others are cold worked

Table 2 Measured yield strength of angle steel (MPa).

\begin{tabular}{c|c|c|c}
\hline Hot-rolled Angle Steel L25×3 & $\begin{array}{c}\text { Cold-worked Angle } \\
\text { Steel, } 1.5 \mathrm{~mm} \text { thick }\end{array}$ & $\begin{array}{c}\text { Cold-worked Angle } \\
\text { Steel, } 1 \mathrm{~mm} \text { thick }\end{array}$ & $\begin{array}{c}\text { Cold-worked Angle } \\
\text { Steel, 0.8mm thick }\end{array}$ \\
\hline 344 & 313 & 336 & 342 \\
\hline
\end{tabular}

Table 3 Wire loads under normal working condition.

\begin{tabular}{c|c|c|c}
\hline \multicolumn{2}{c|}{ Conductors $(\mathrm{N})$} & \multicolumn{2}{c}{ Ground Wire $(\mathrm{N})$} \\
\hline Vertical & Horizontal & Vertical & Horizontal \\
\hline 33015 & 0 & 10355 & 0 \\
\hline
\end{tabular}




\section{List of Figures}

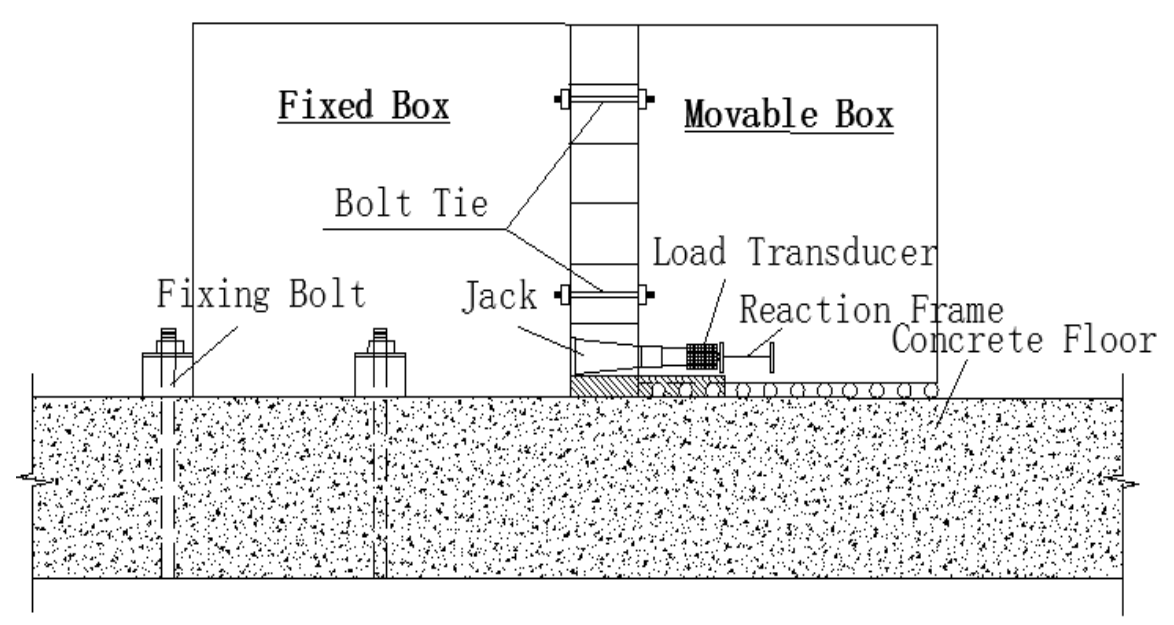

(a) Elevation of the test setup

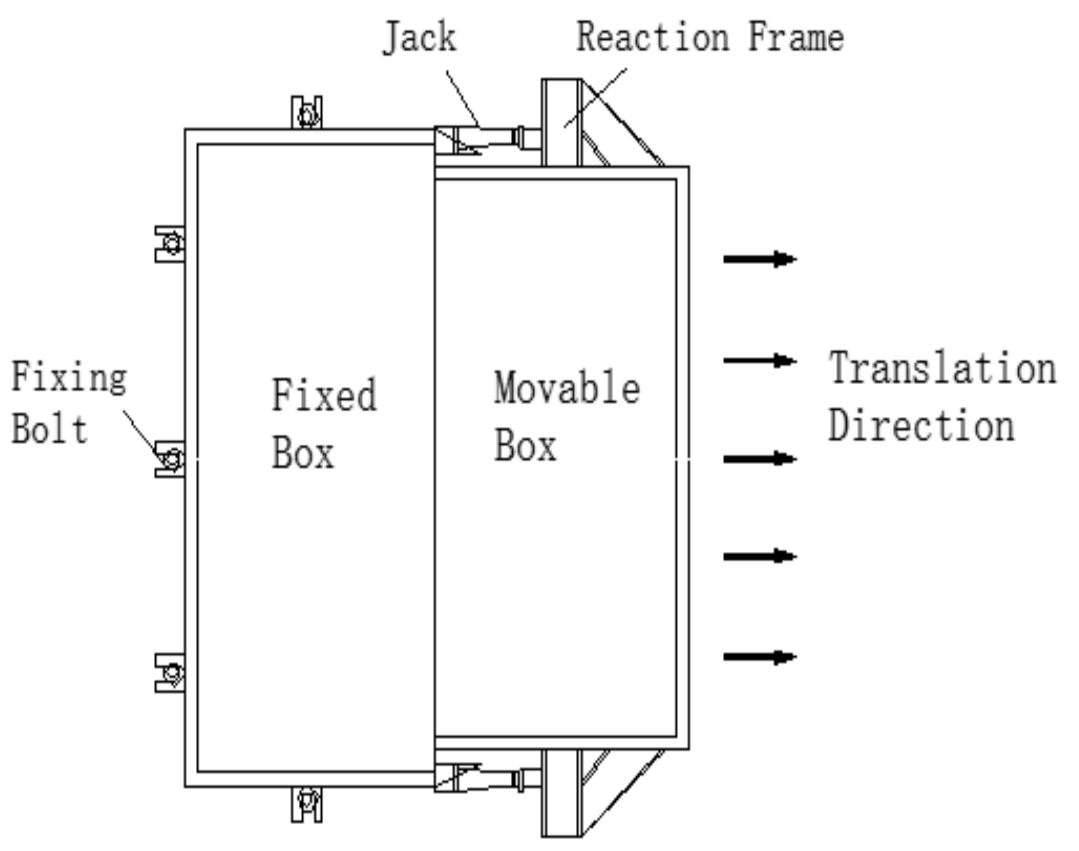

(b) Plan view of the test setup

Fig. 1 Test rig for simulating horizontal ground movements. 


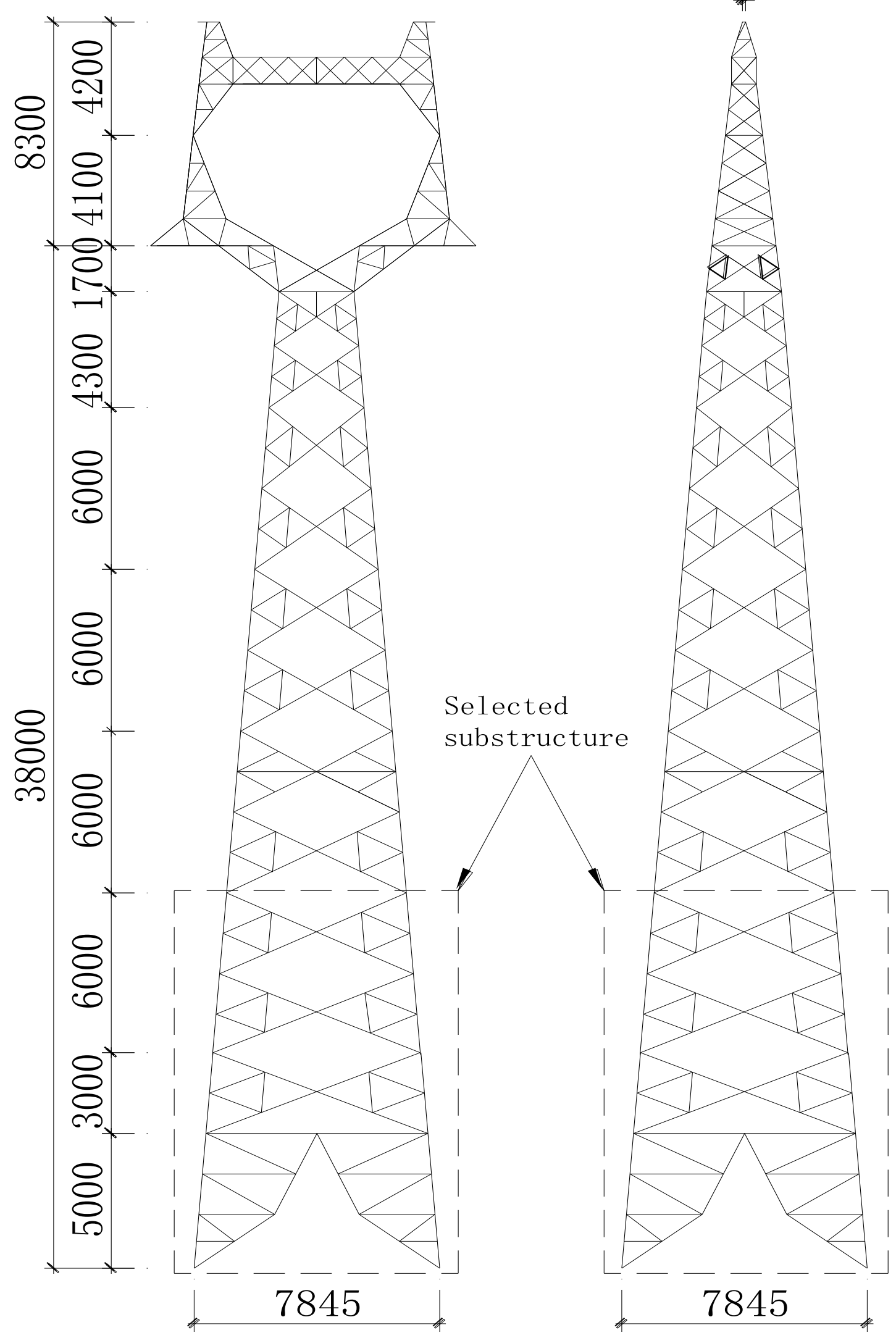

Fig. 2 The prototype of the $220 \mathrm{kV}$ transmission tower used (all dimensions in $\mathrm{mm}$ ). 


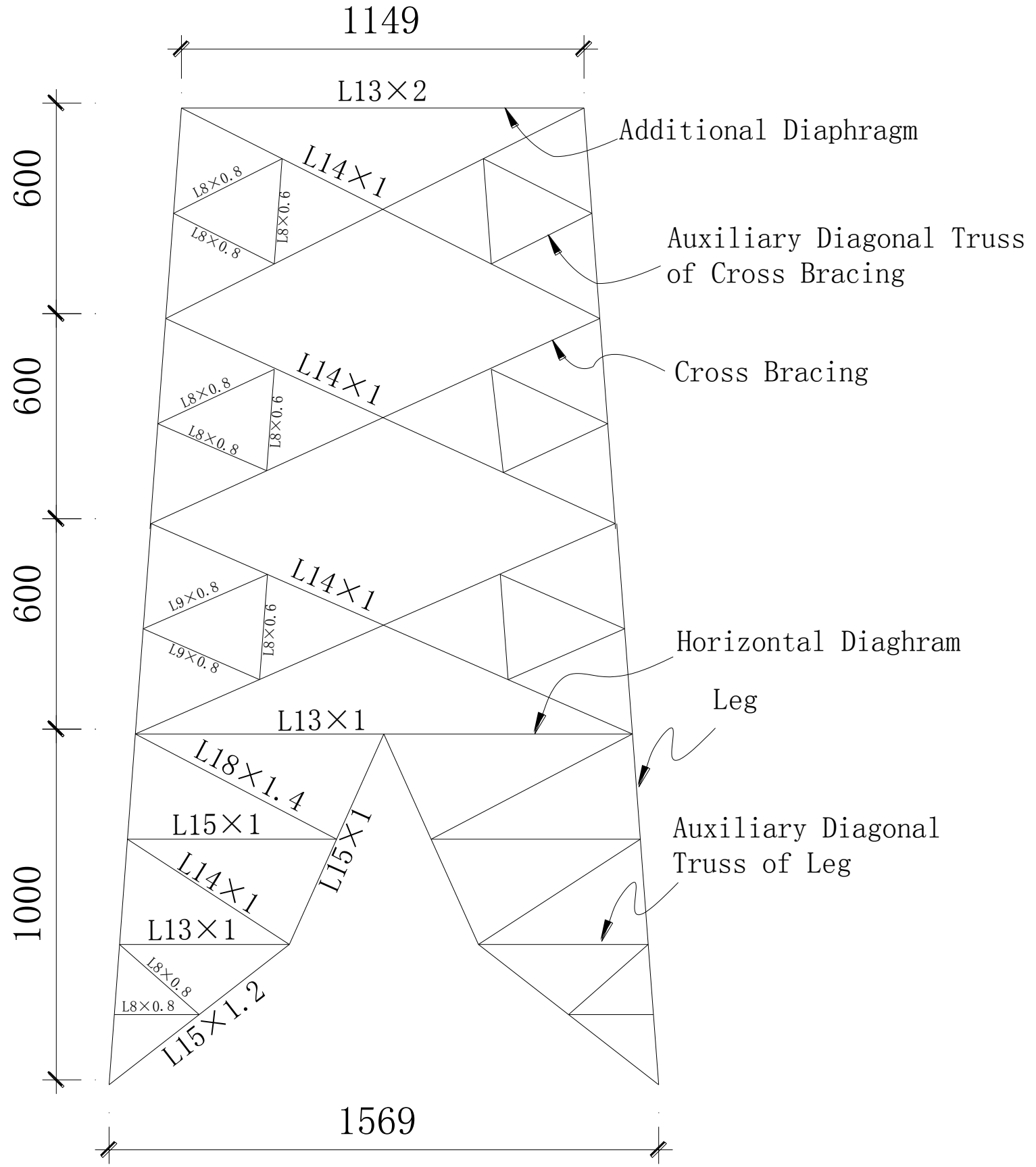

Fig.3 Details of the 1:5 scaled tower model (all dimensions in $\mathrm{mm}$ ). 


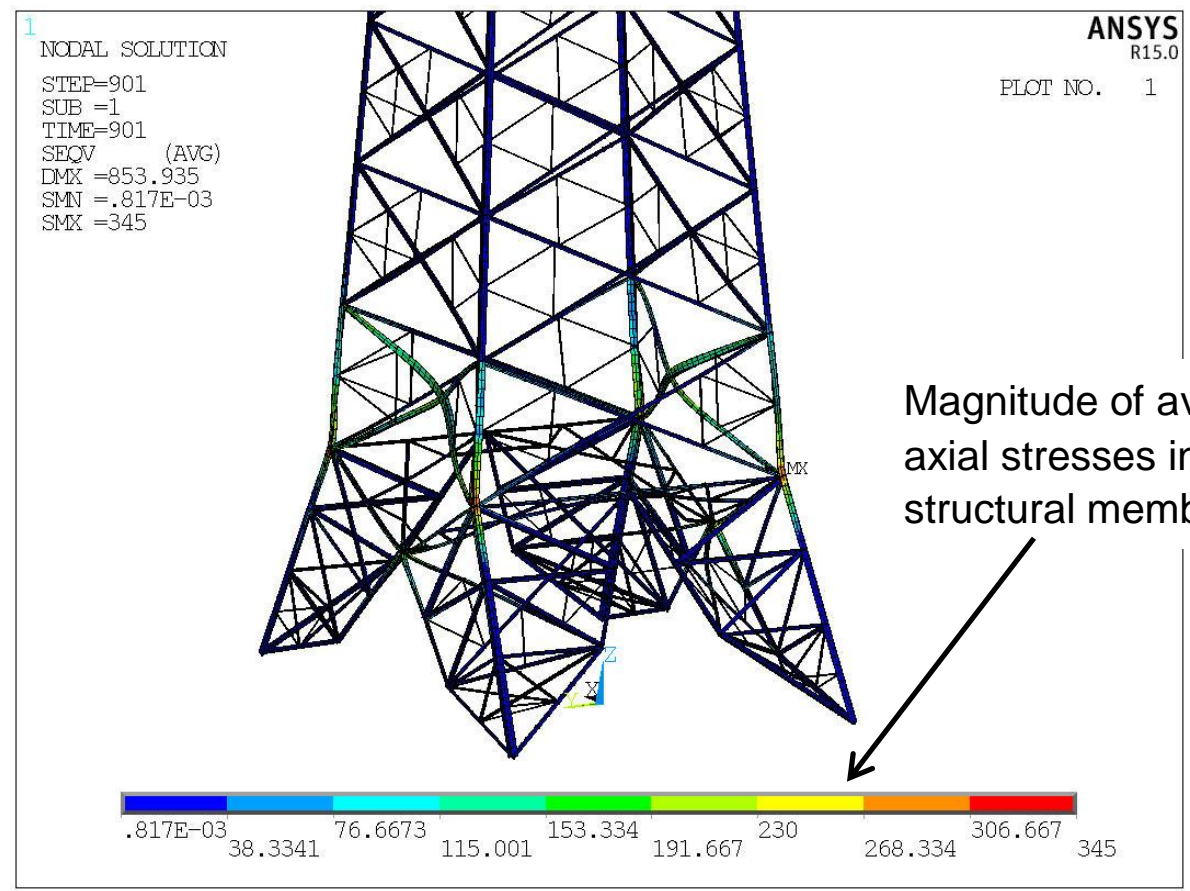

(a)

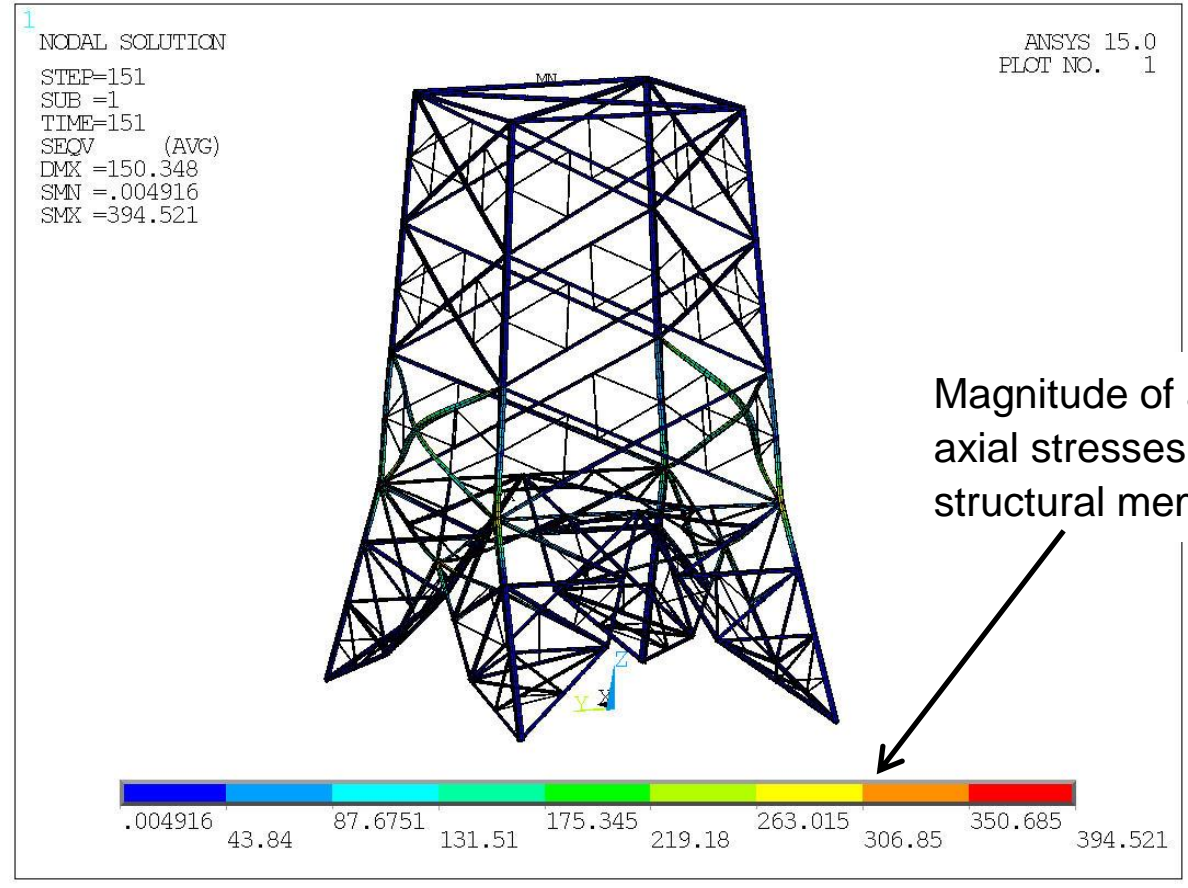

(b)

Fig.4 Deformed diagrams of: (a) the sub-structure of whole tower analysed; (b) the scaled tower model (magnified by 5 times). 


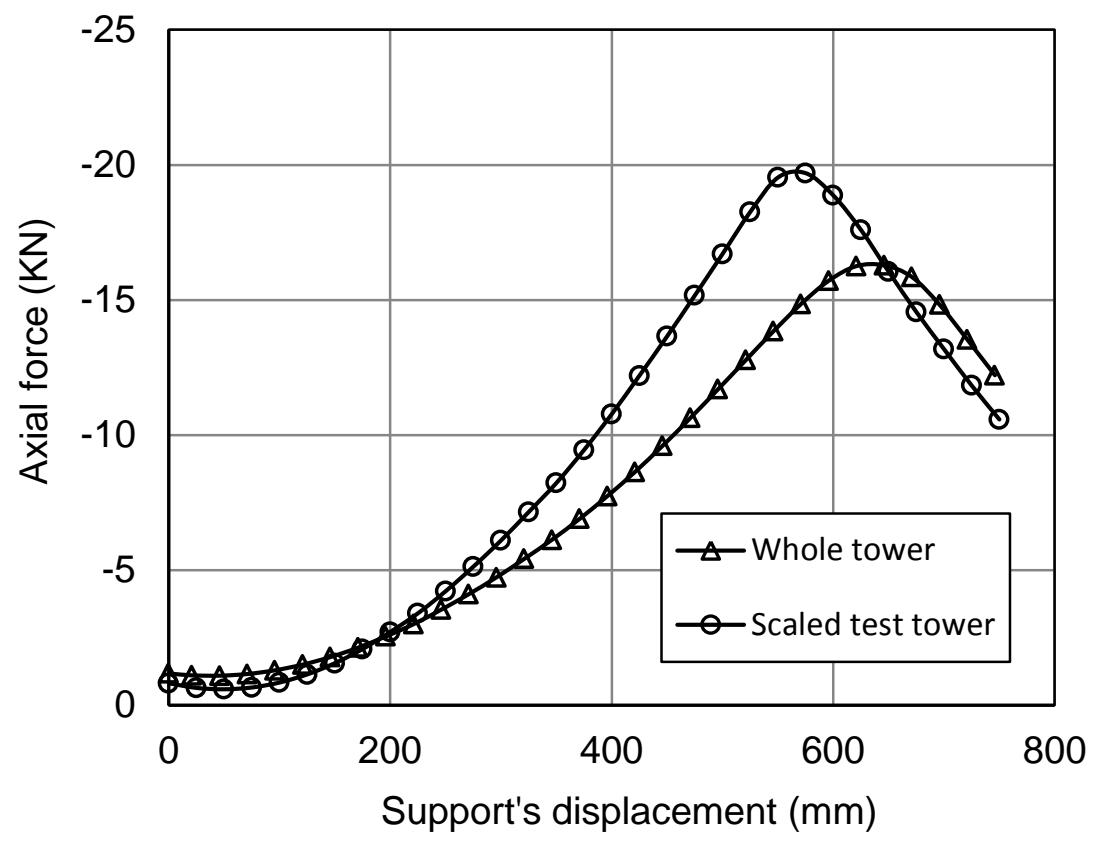

(a) Axial force in the first bracing member AX1

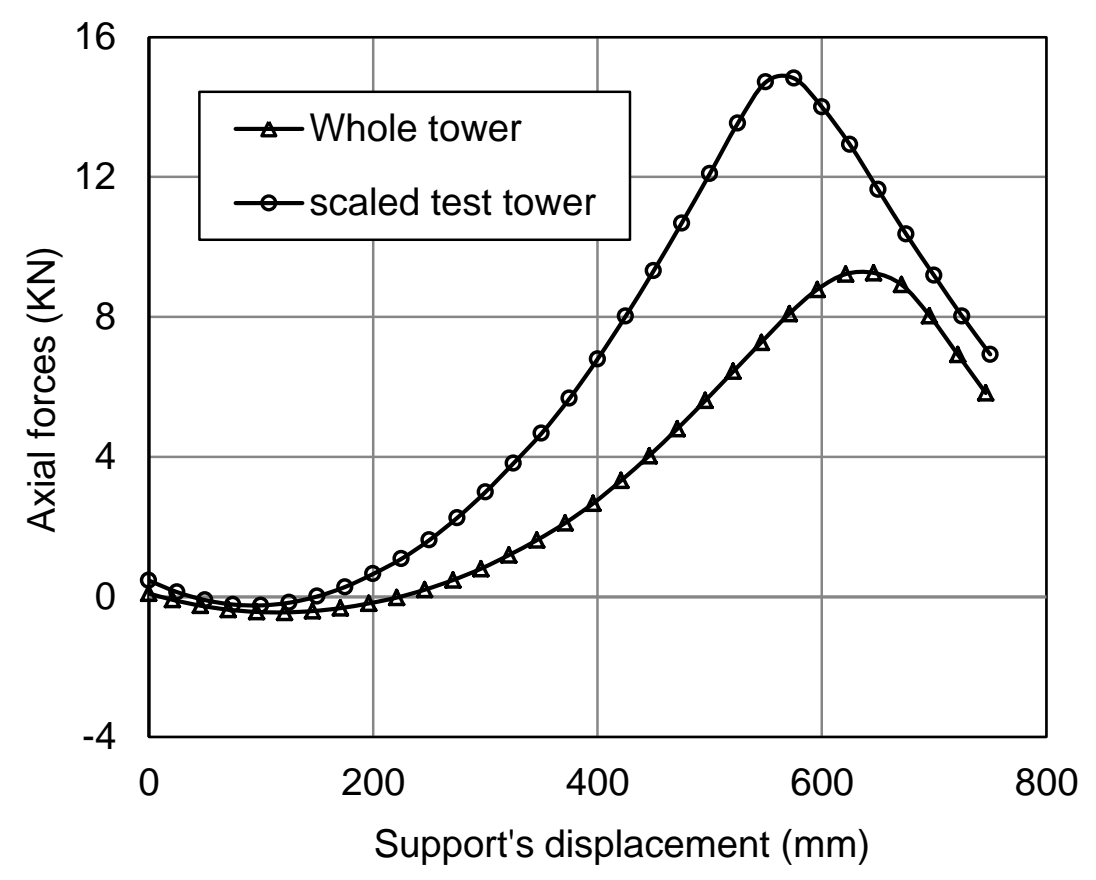

(b) Axial force in the second bracing member AX3 


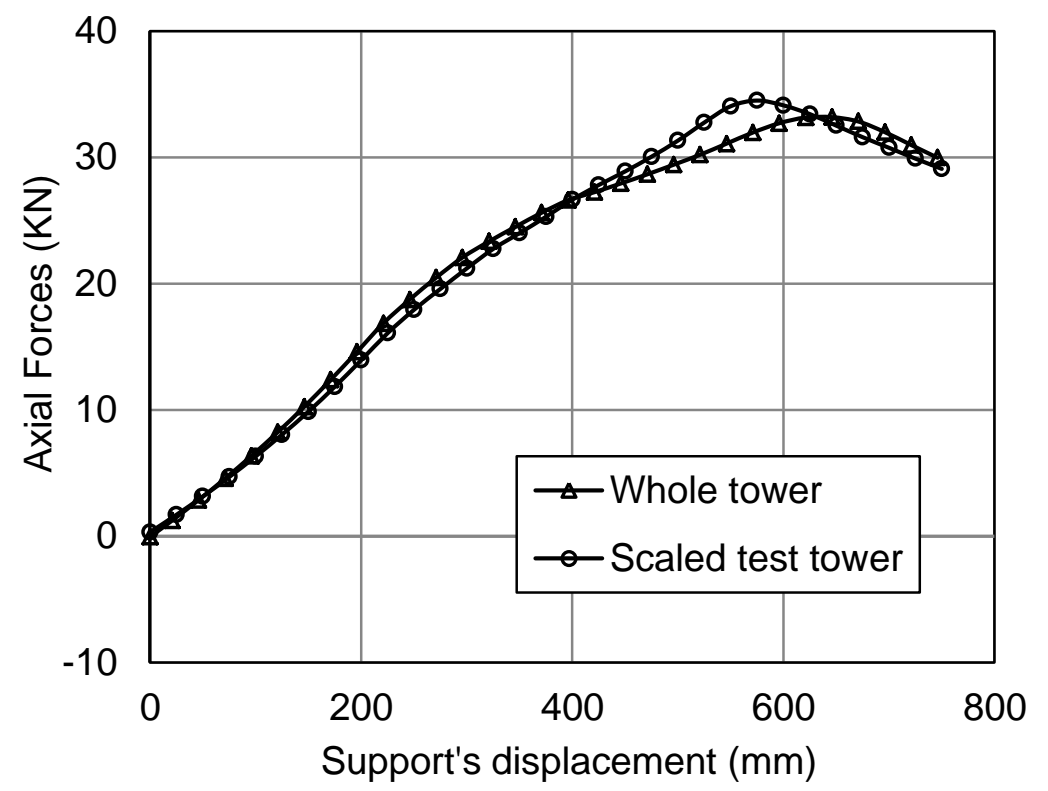

(c) Axial force in the horizontal diaphragm member AW1

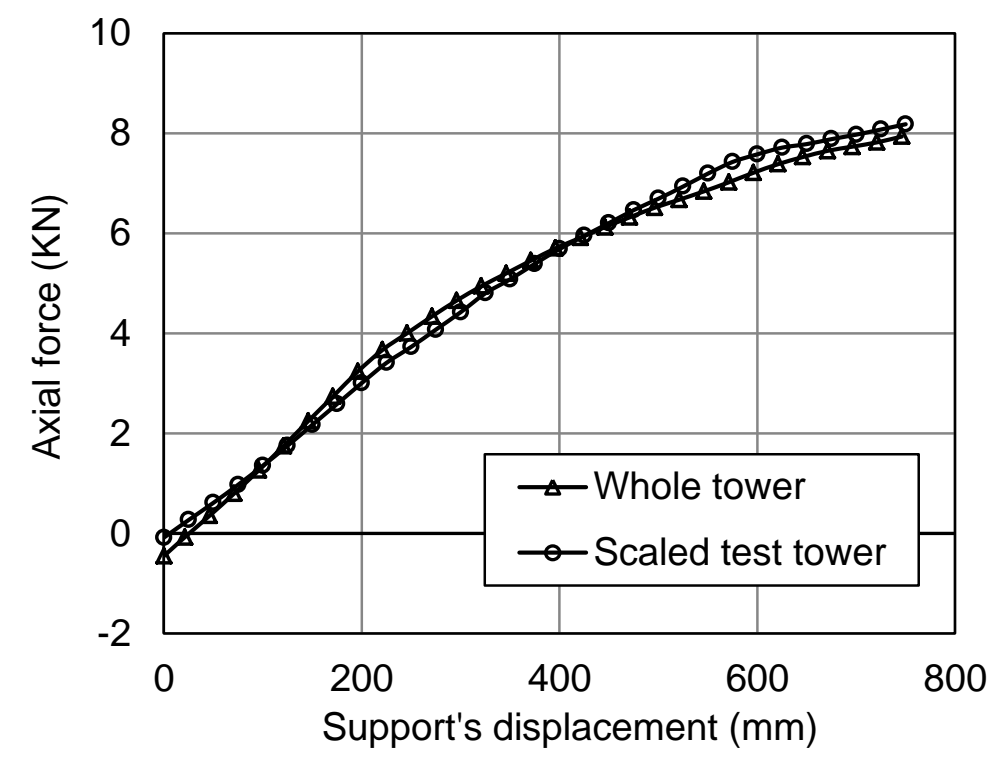

(d) Axial force in the diagonal truss member AL1 to the tower's leg 1 


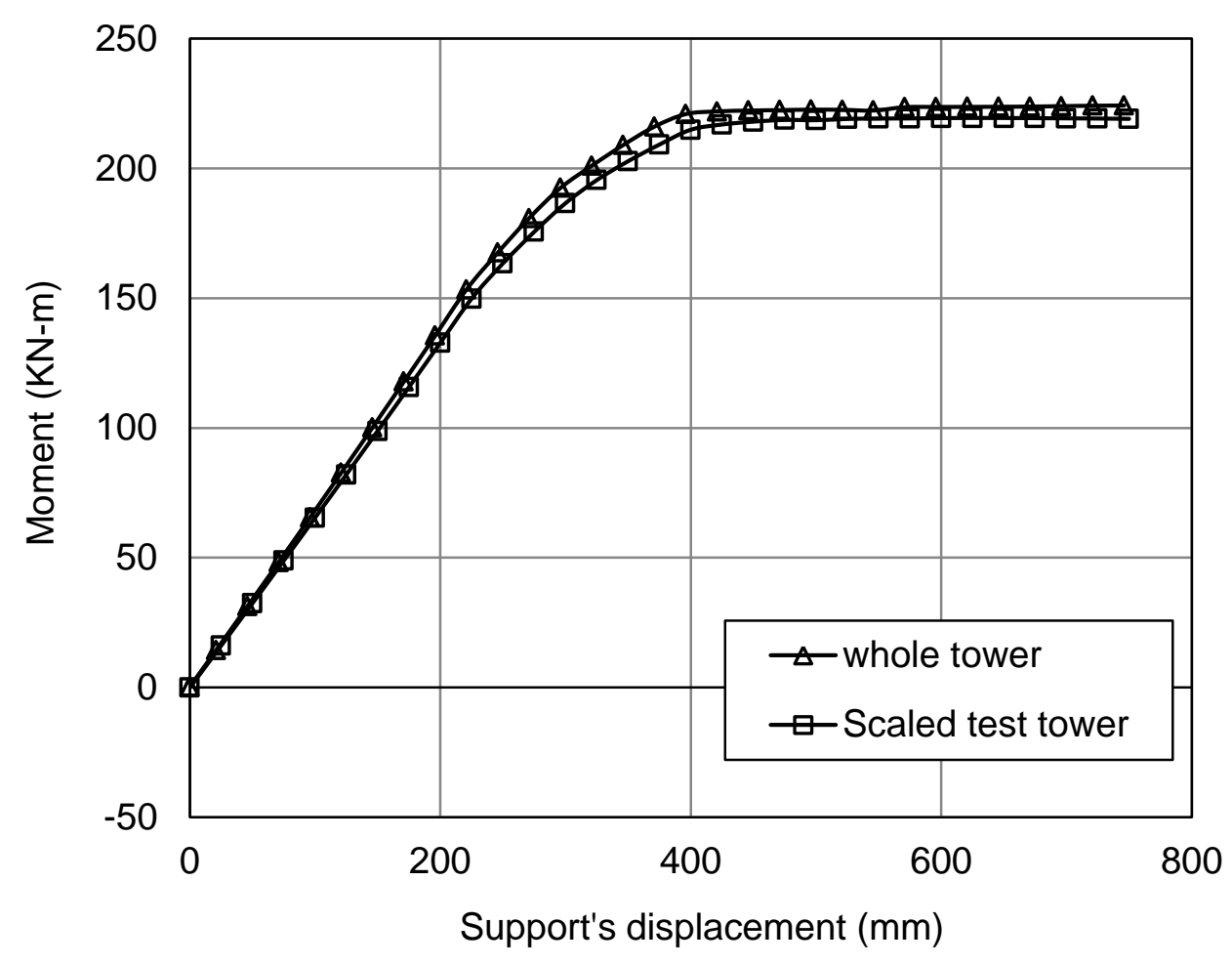

(e) Moment at the position of L24 of the tower's leg 2

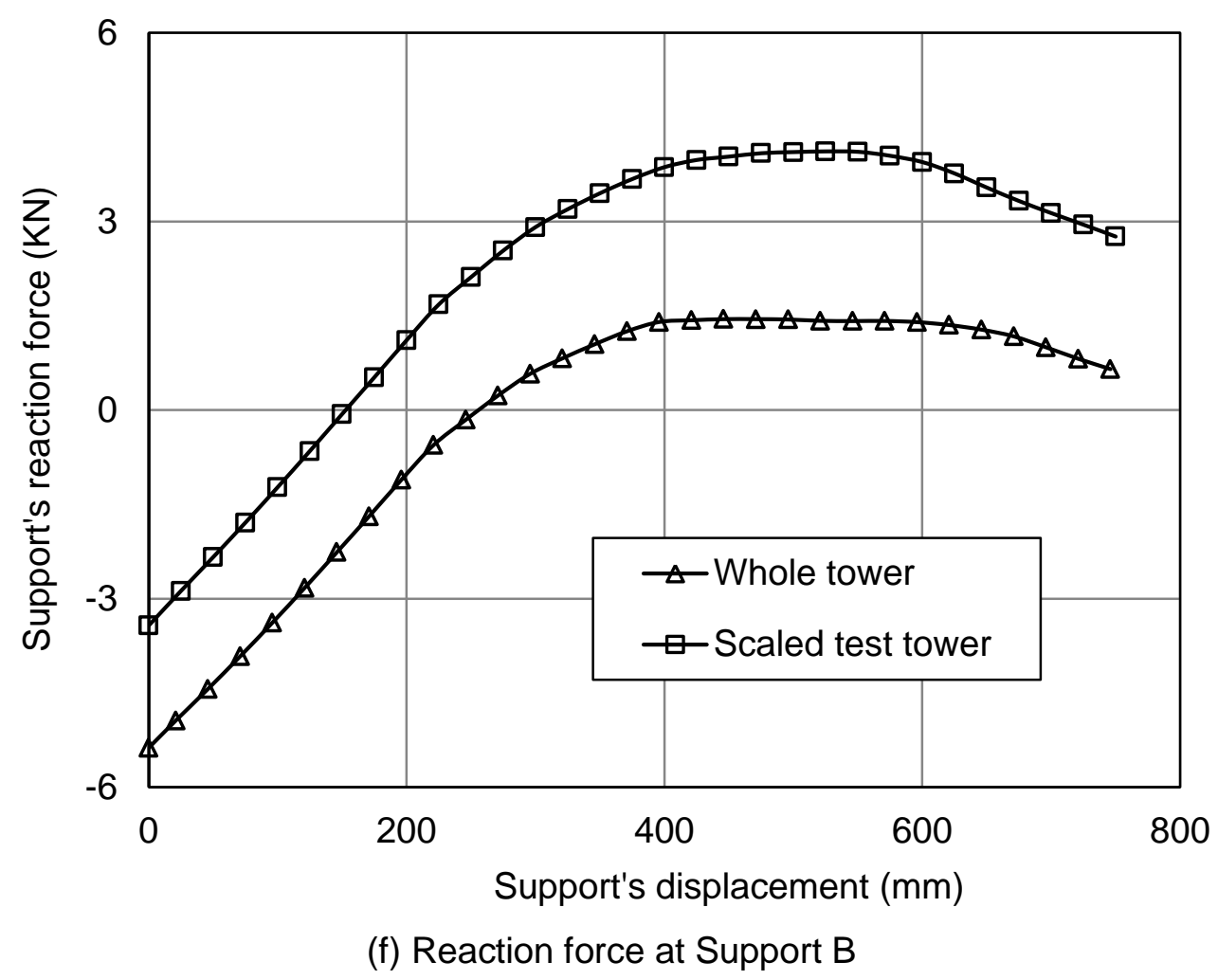

Fig.5 Comparison of the predicted forces against the support's displacements between the whole tower and scaled test tower model. 


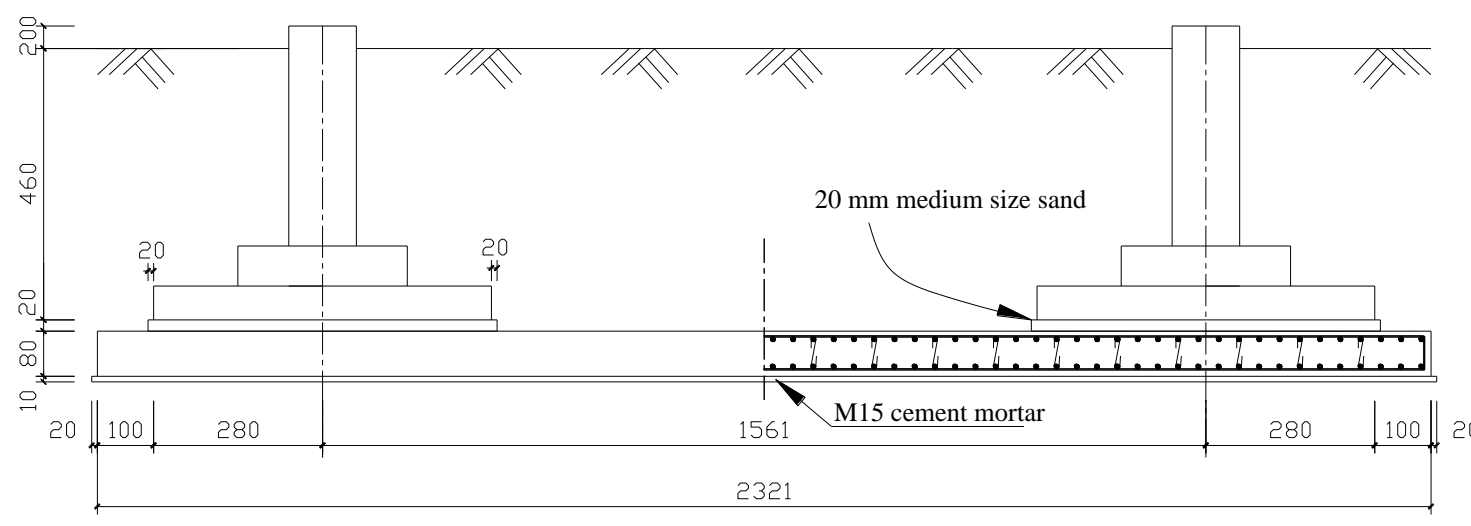

(a) Hybrid slab foundation model

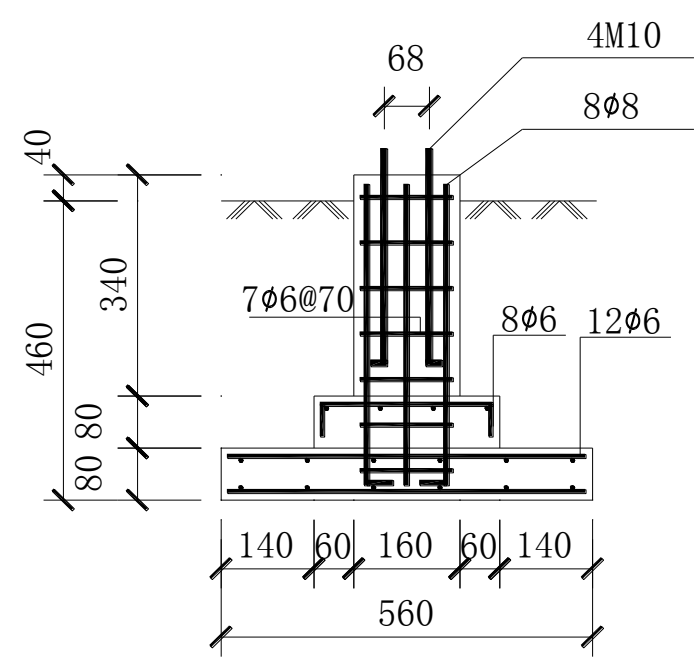

(b) Isolated foundation model

Fig. 6 Details of the proposed hybrid slab foundation model (all dimensions in $\mathrm{mm}$ ). 


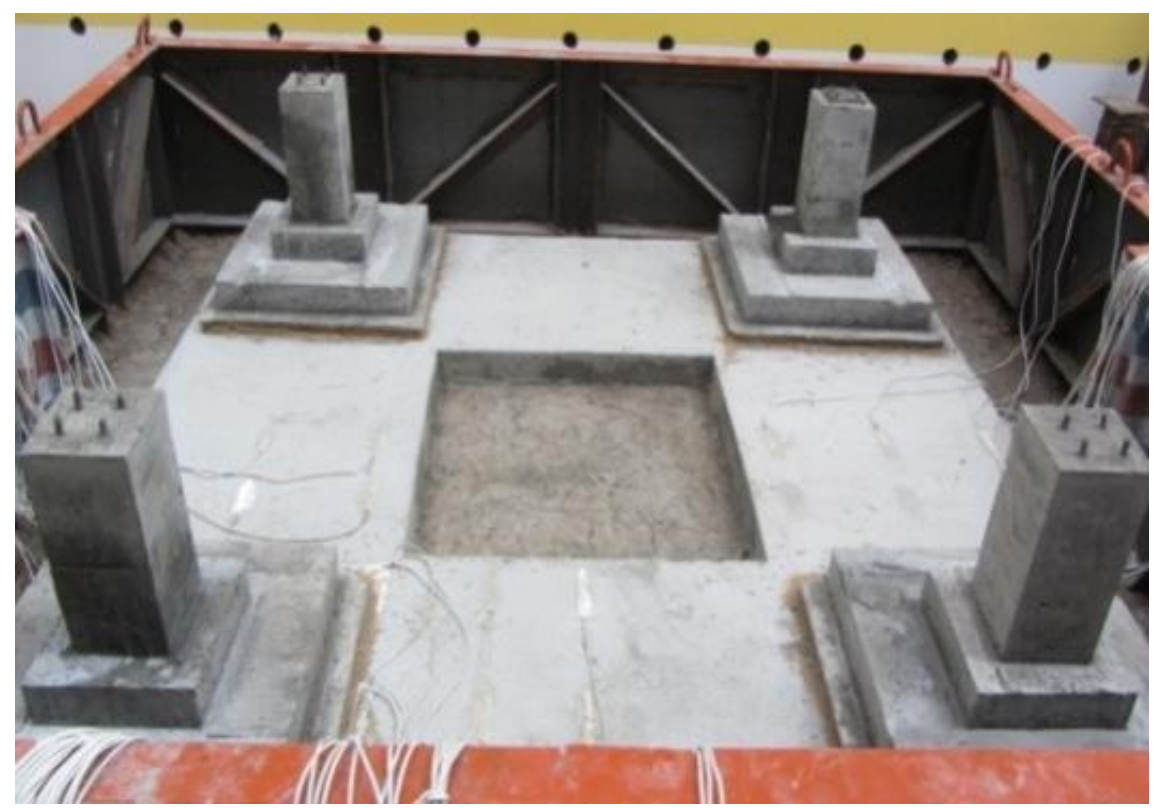

Fig. 7 Completed hybrid slab foundation.

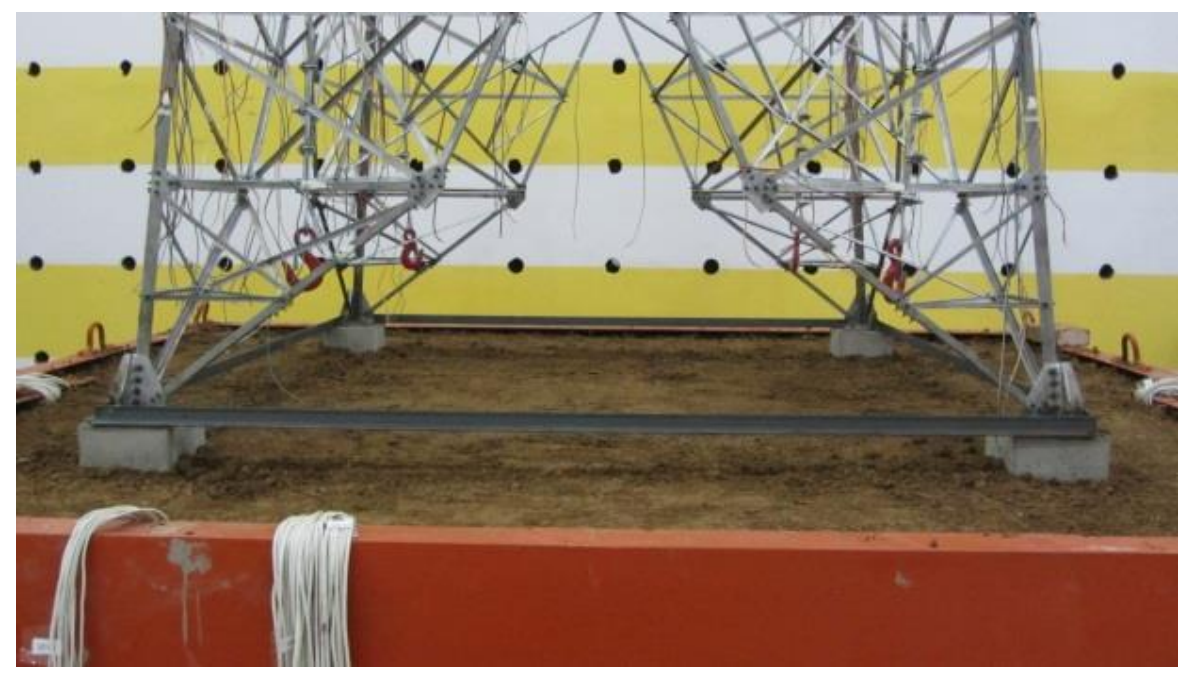

Fig. 8 The completed test setup. 


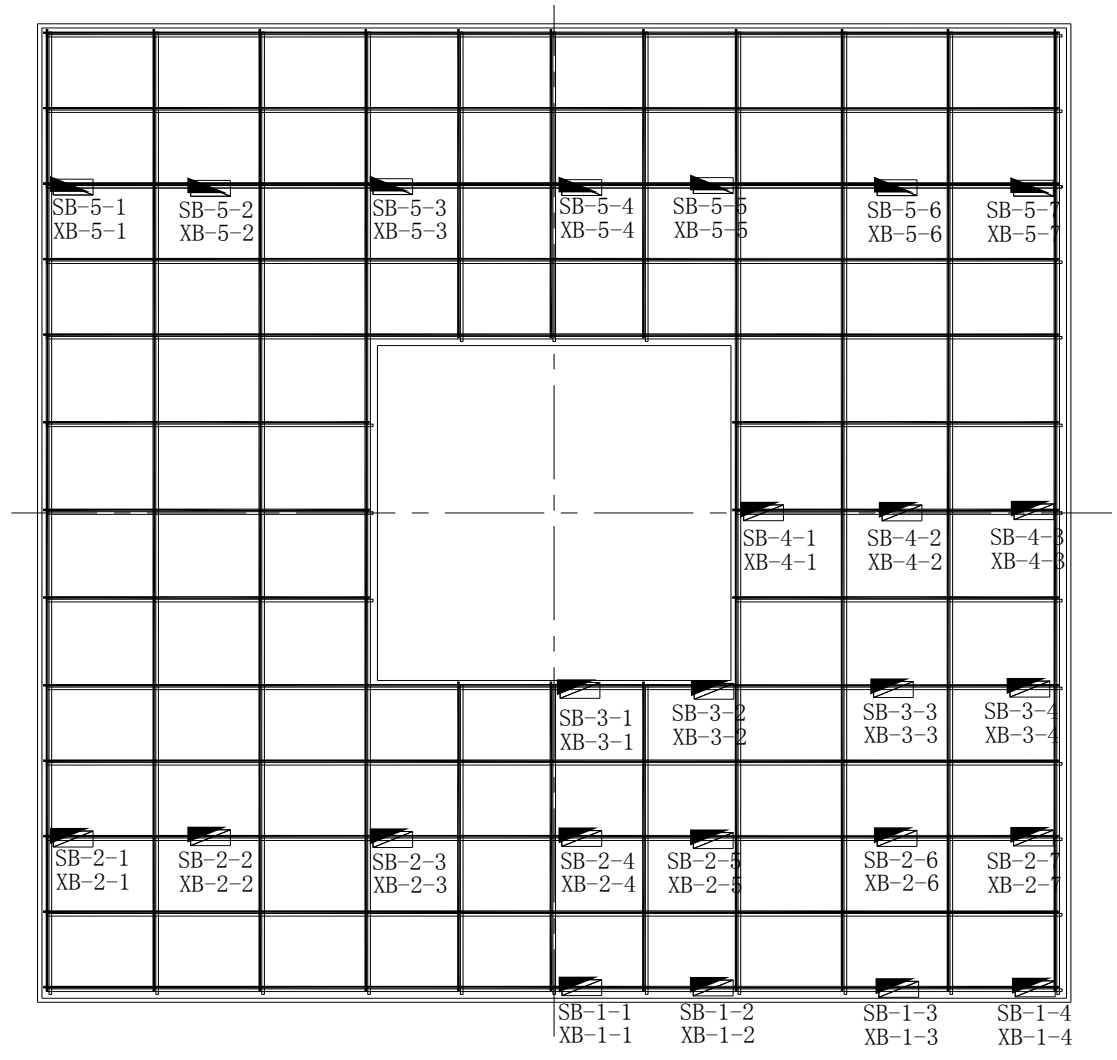

Fig. 9 Arrangement of strain gauges attached to the reinforcing steel bars in the foundation RC slab (SB-top layer; XB-bottom layer).

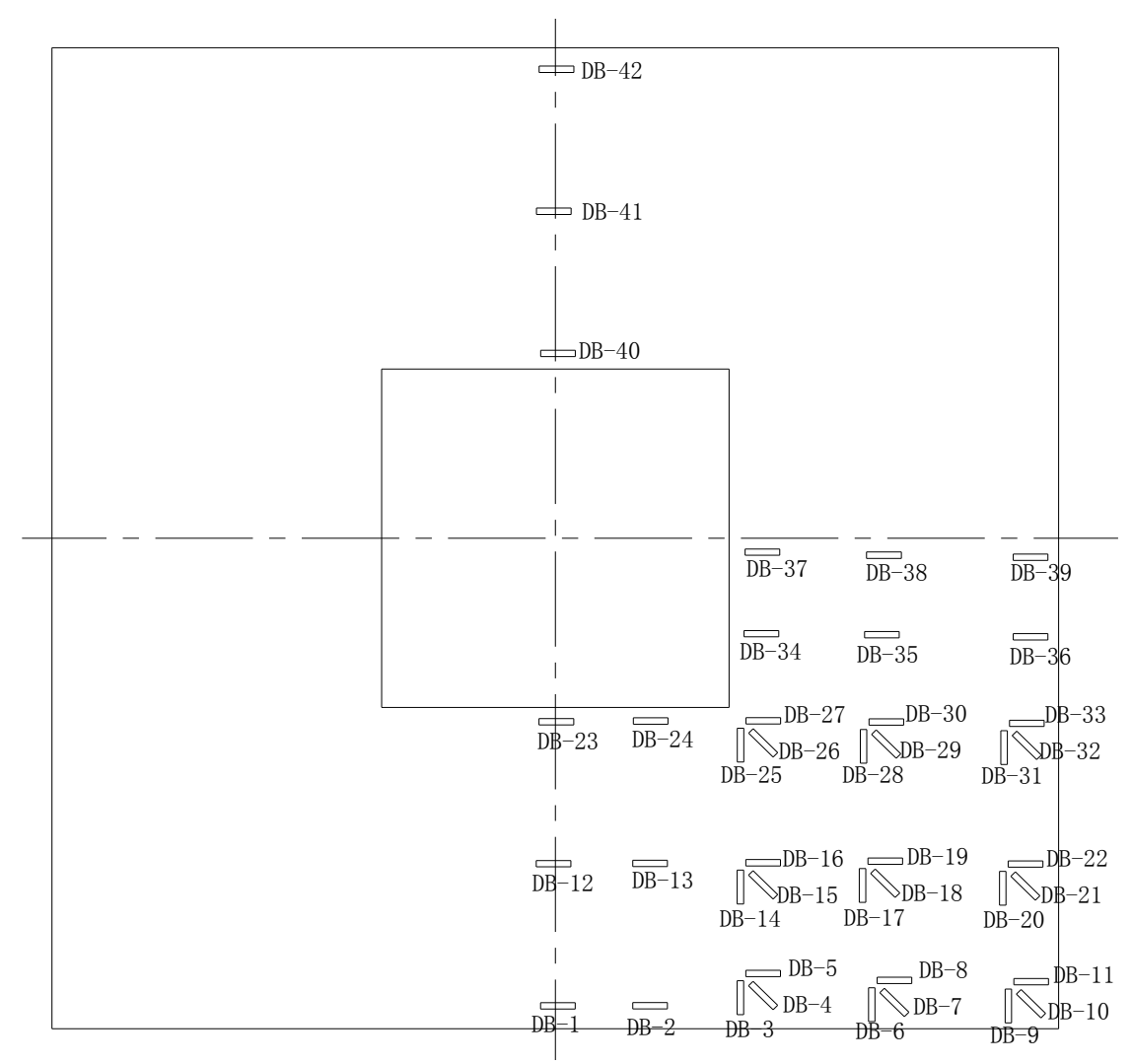

Fig. 10 Arrangement of strain gauges on the surface of the foundation RC slab. 


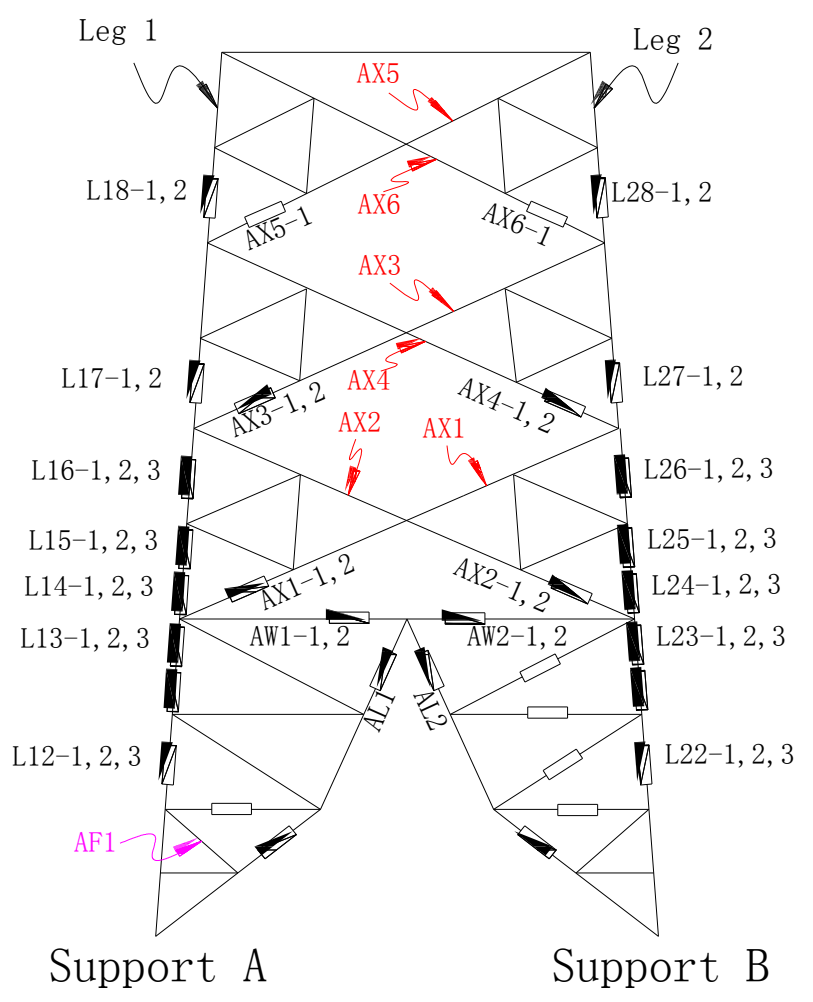

(a) Measuring positions and labels in Plane A-B

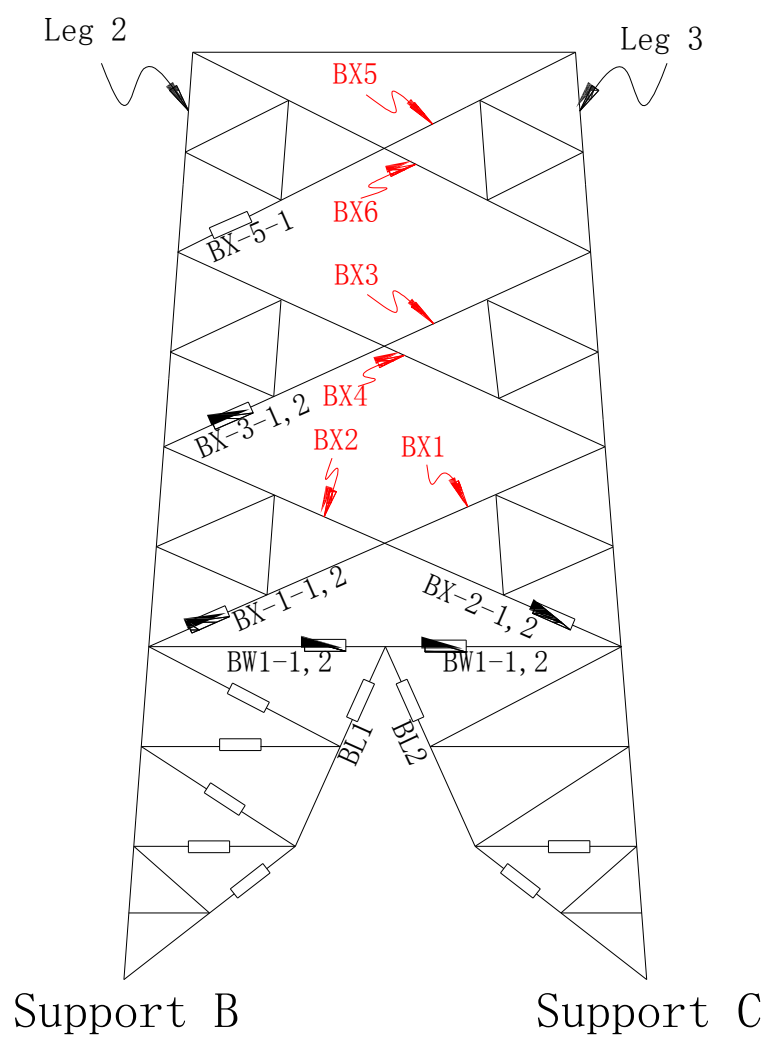

(b) Measuring positions and labels in Plane B-C 

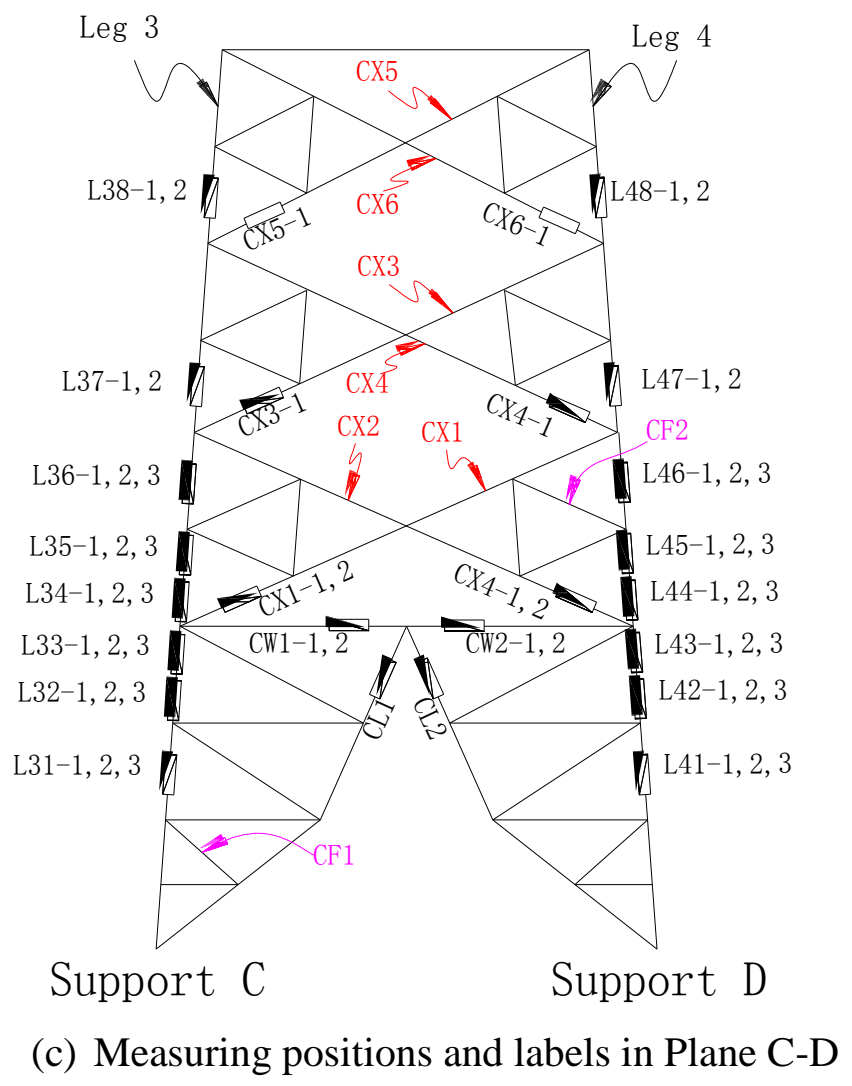

L e g 4

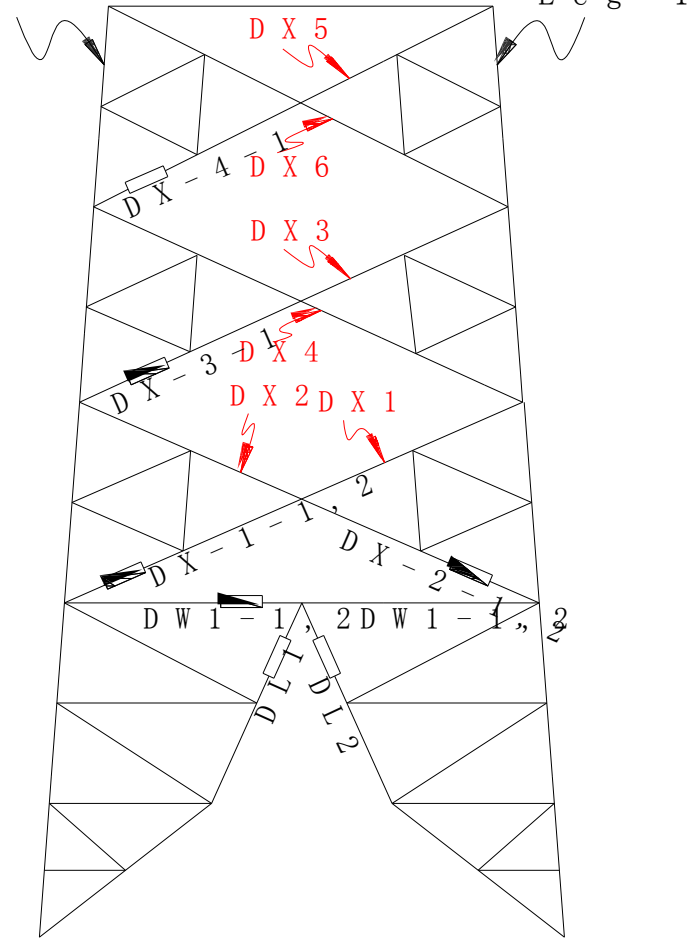

S u p p or t D

S u p p o r 1

(d) Measuring positions and labels in Plane D-A 


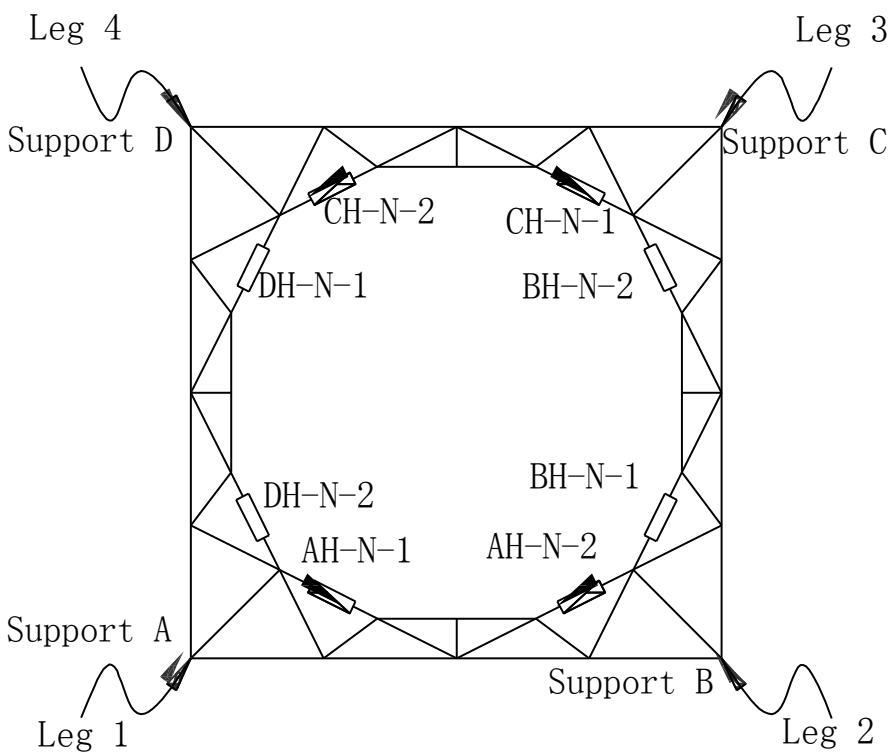

(e) Measuring positions and labels in horizontal diaphragms

Fig. 11 Strain gauges arrangement and member's labels on the scaled tower model.

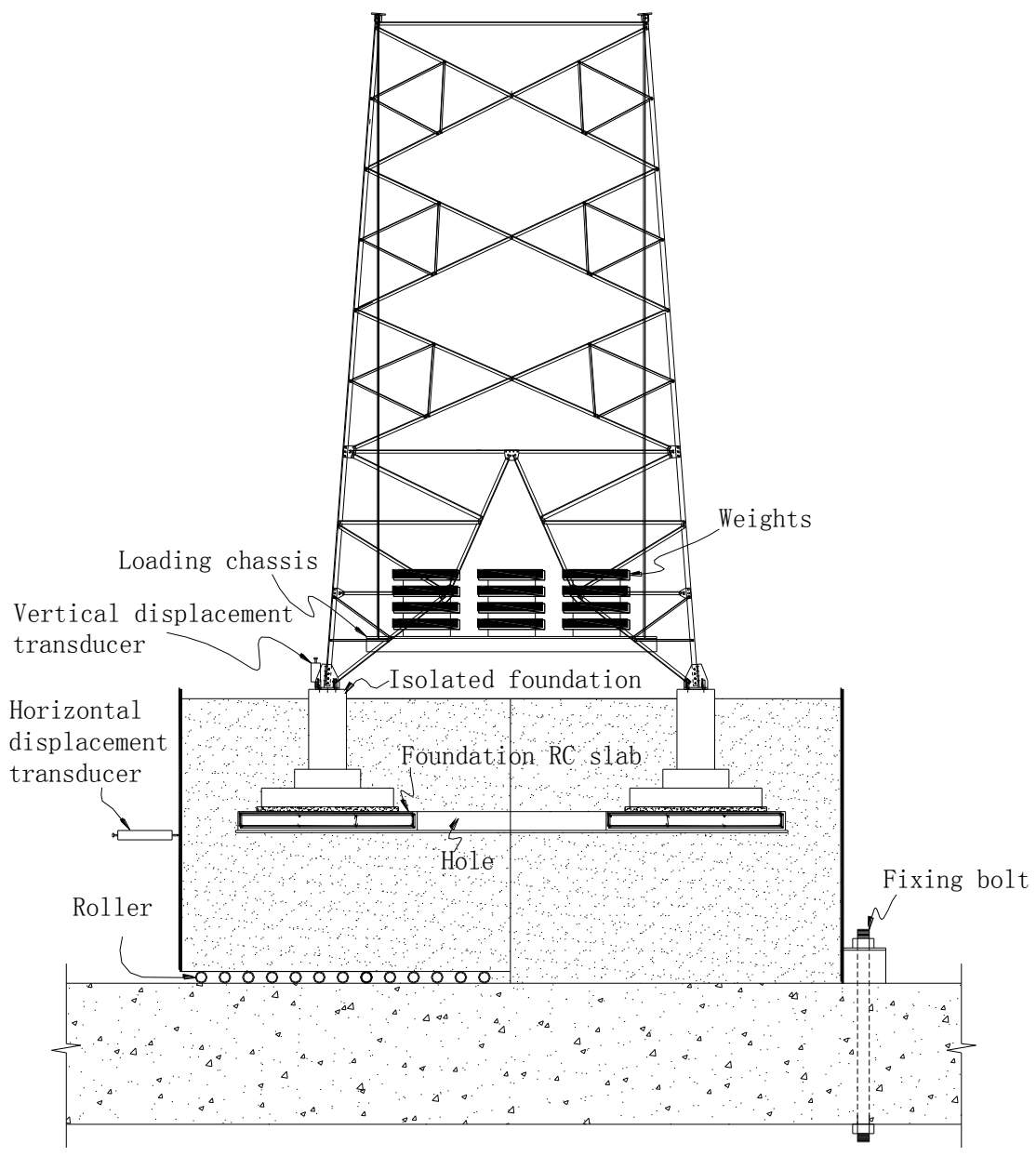

Fig. 12 Elevation of the integrated test setup. 


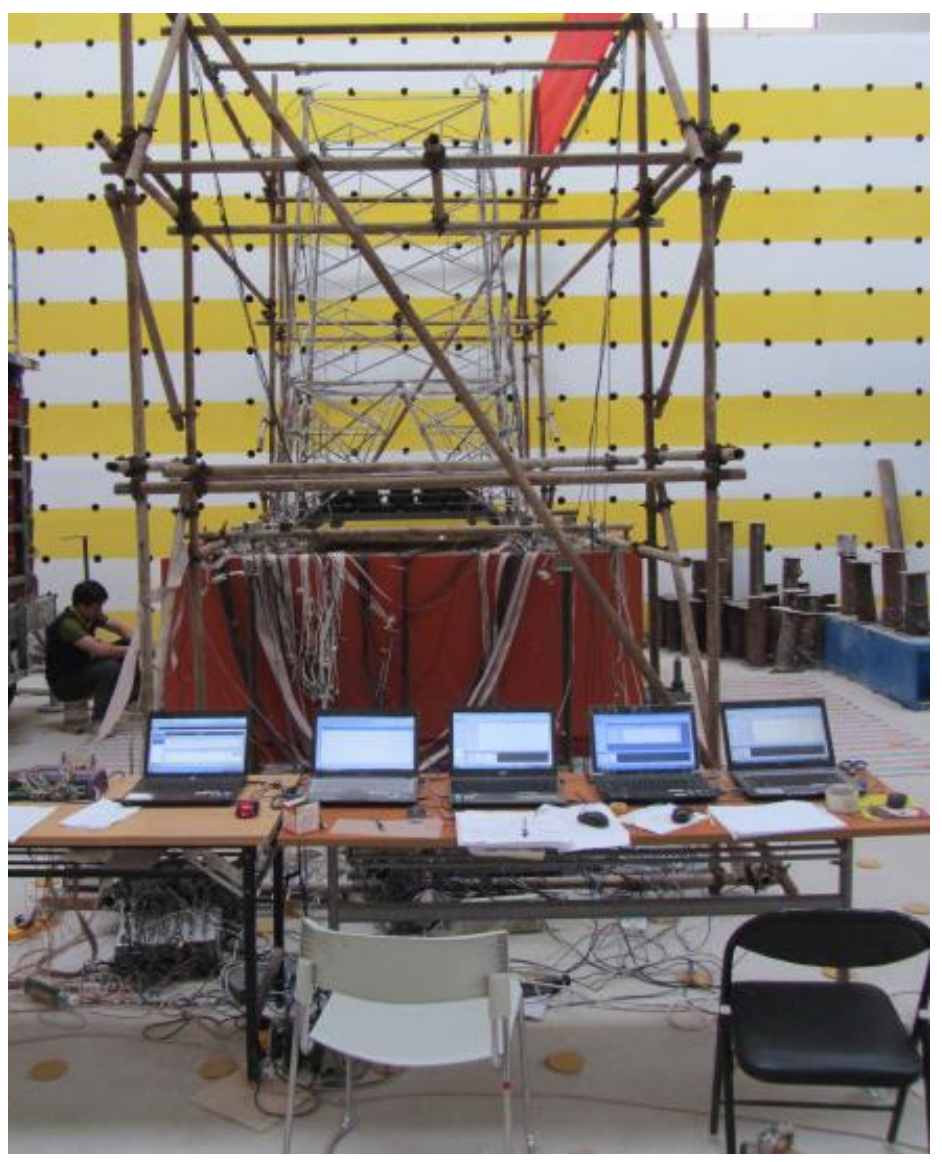

Fig. 13 Panorama view of the test.

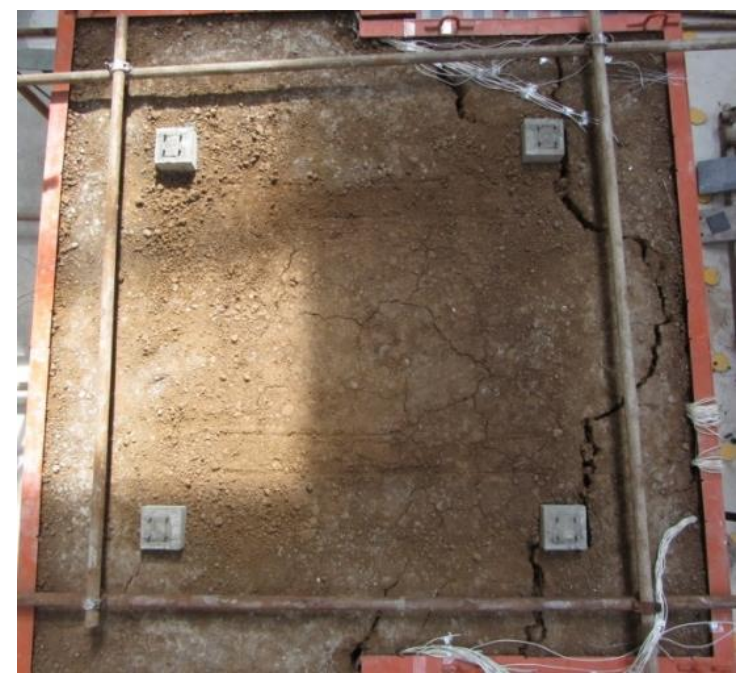

(a) Cracking pattern within the foundation soil 


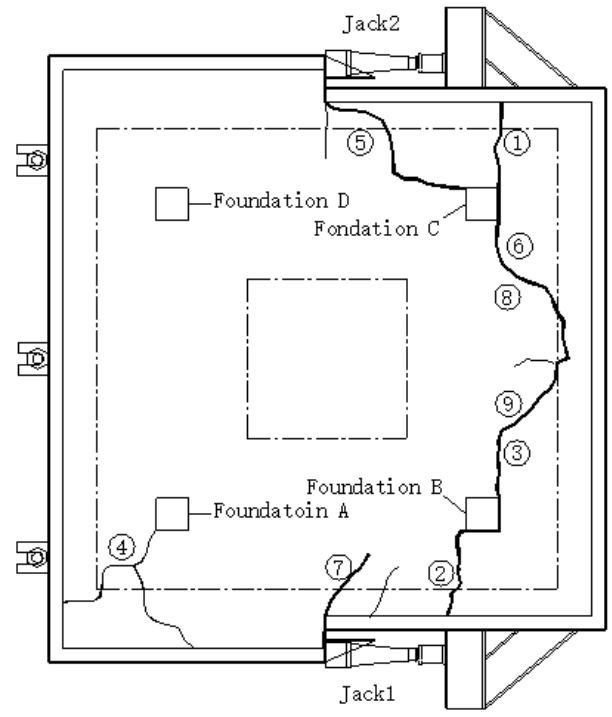

(b) Sketch of cracking pattern within foundation soil (plan view)

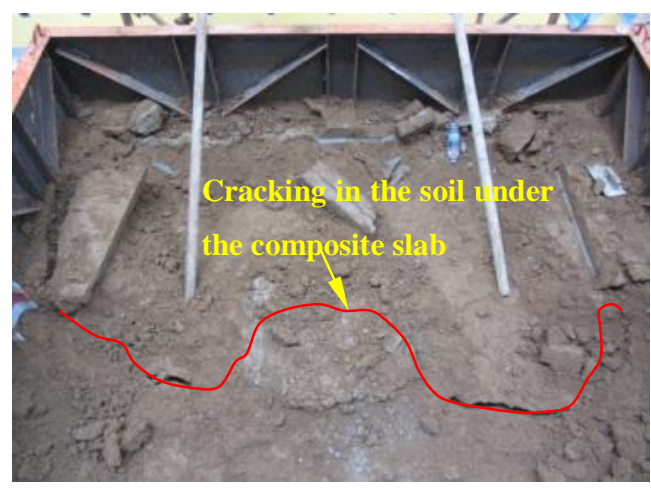

(c) Cracking pattern of foundation soil under the foundation $\mathrm{RC}$ slab 


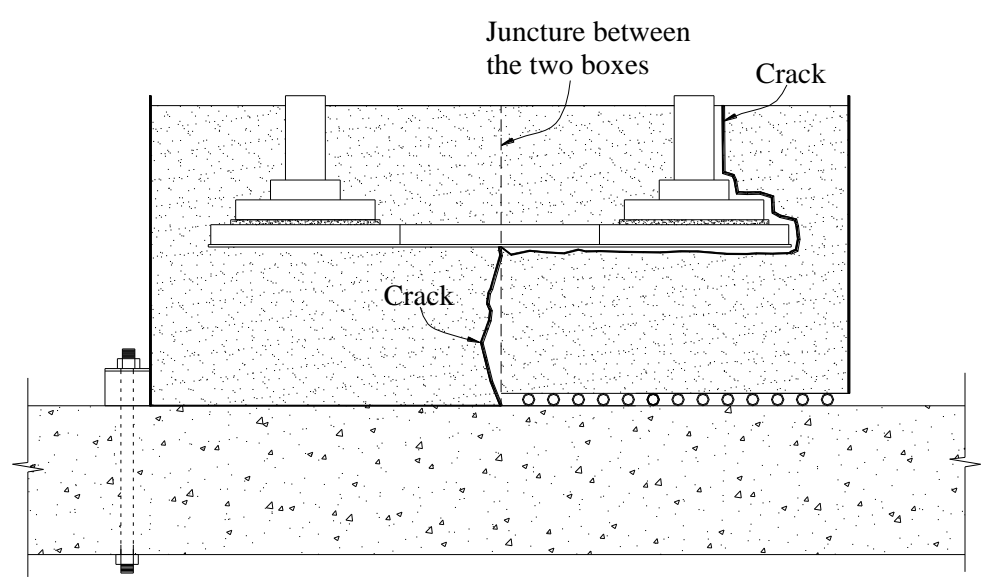

(d) Sketch of the cracking pattern within the soil under the foundation RC slab (Section view)

Fig. 14 Cracking pattern within the foundation soil.

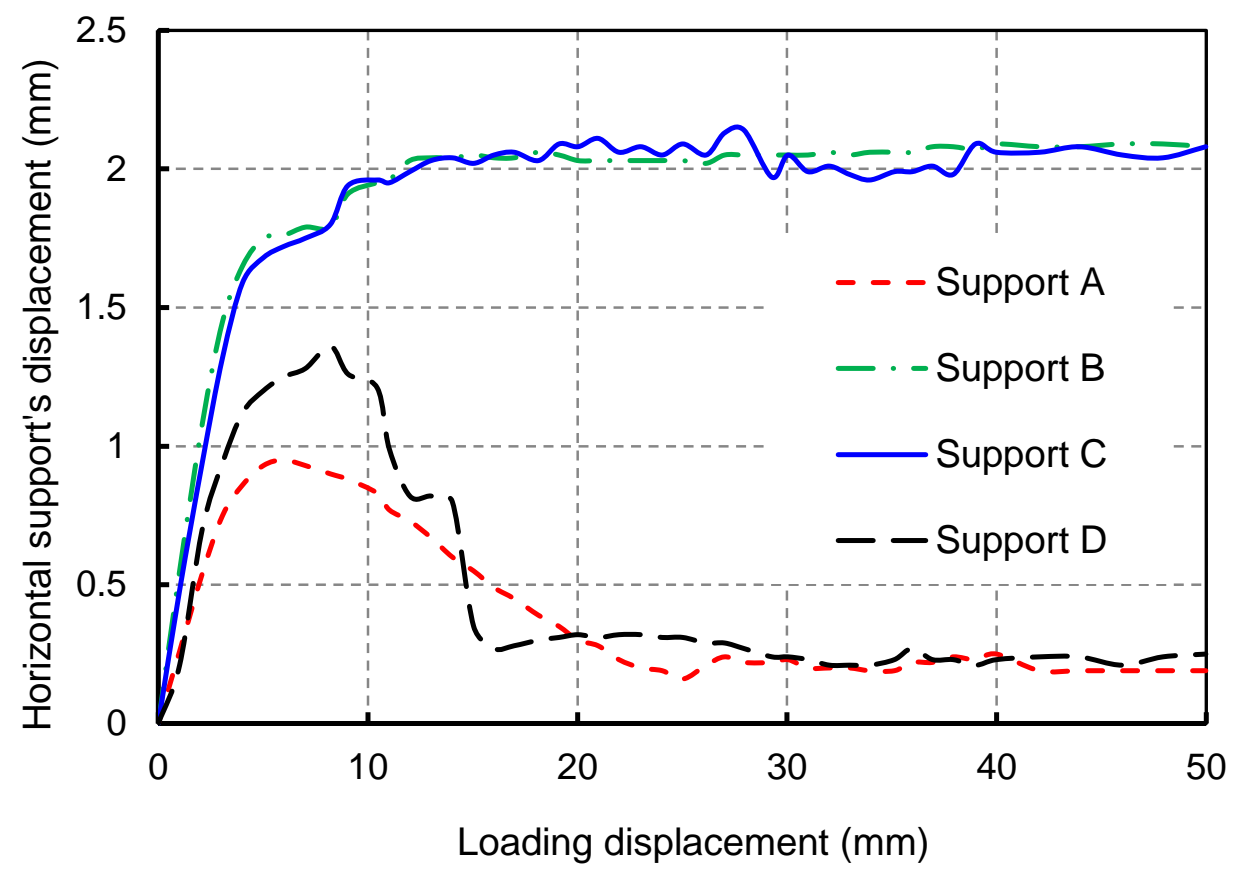

Fig. 15 Horizontal support's displacement against loading displacement. 




Fig. 16 Vertical subsidence of the supports against loading displacement.

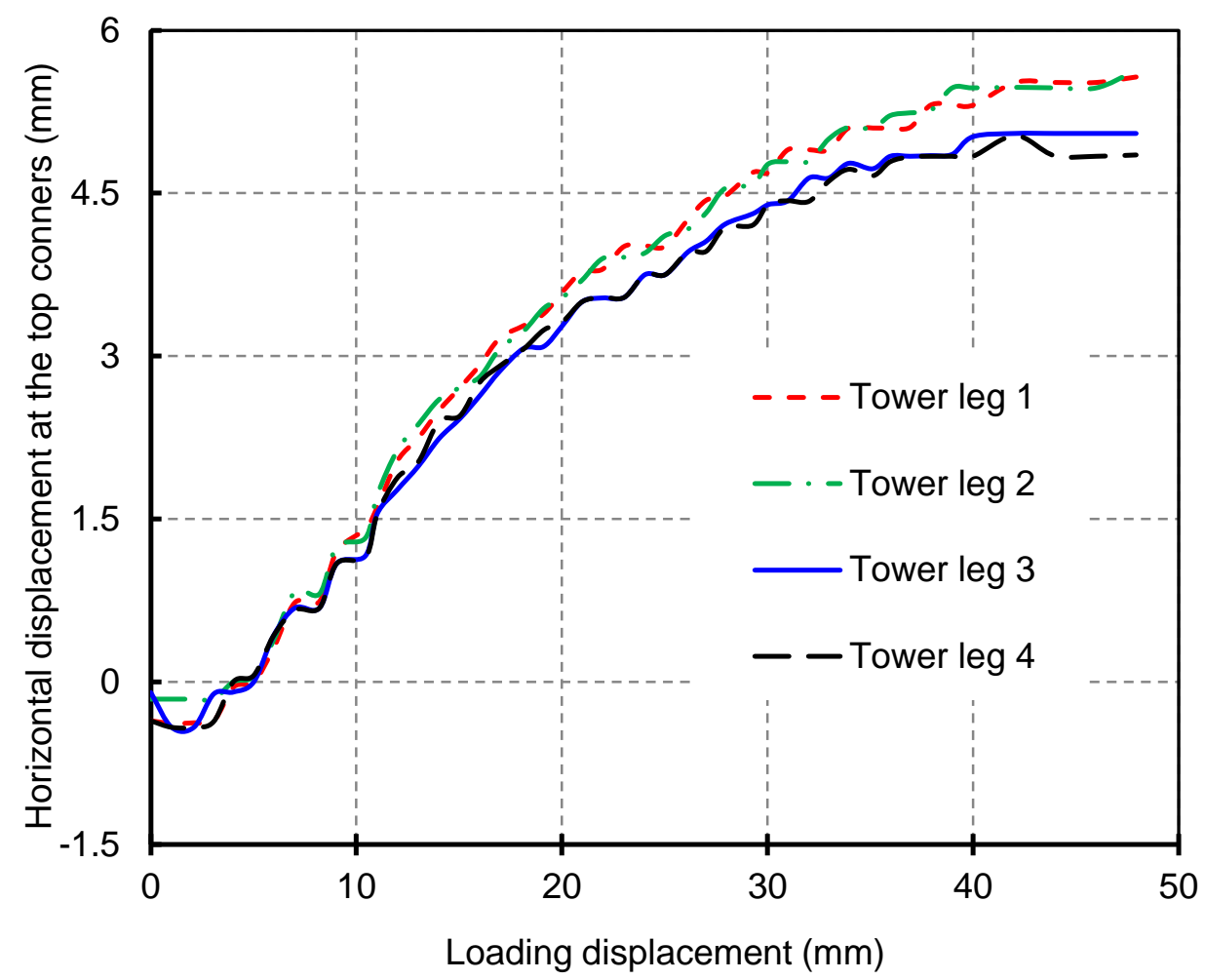

Fig. 17 Horizontal displacements at the top corners of the scaled tower model against loading displacement. 


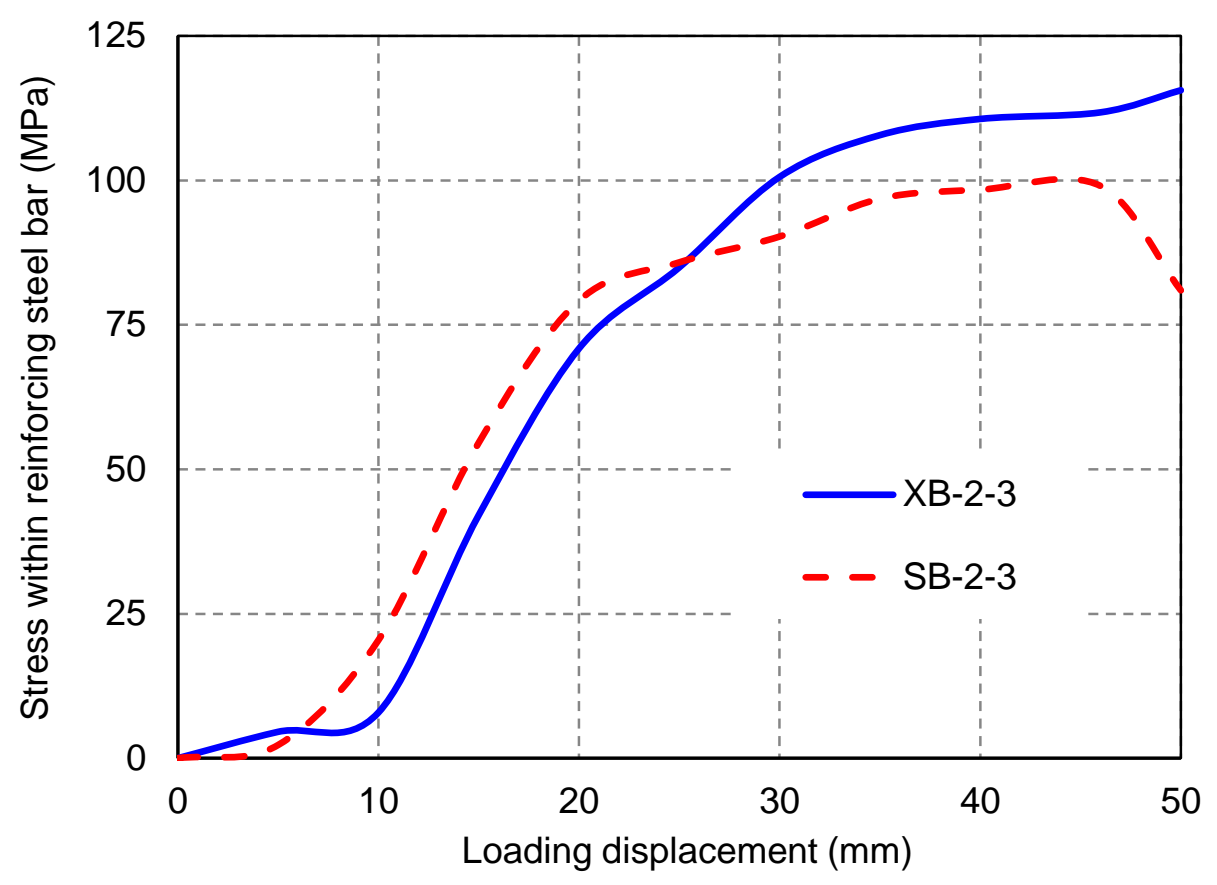

Fig. 18 Stresses within the reinforcing steel bars against loading displacement.

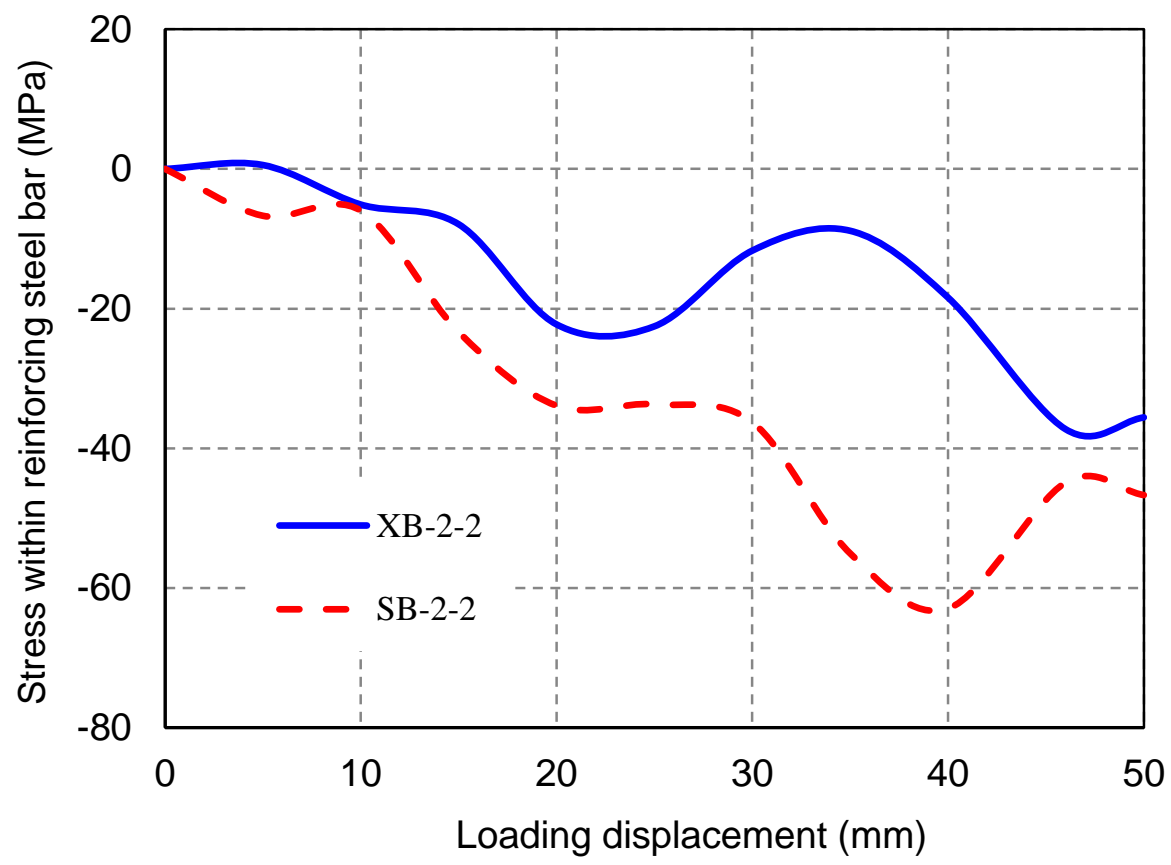

Fig. 19 Stresses within the reinforcing steel bars against loading displacement. 


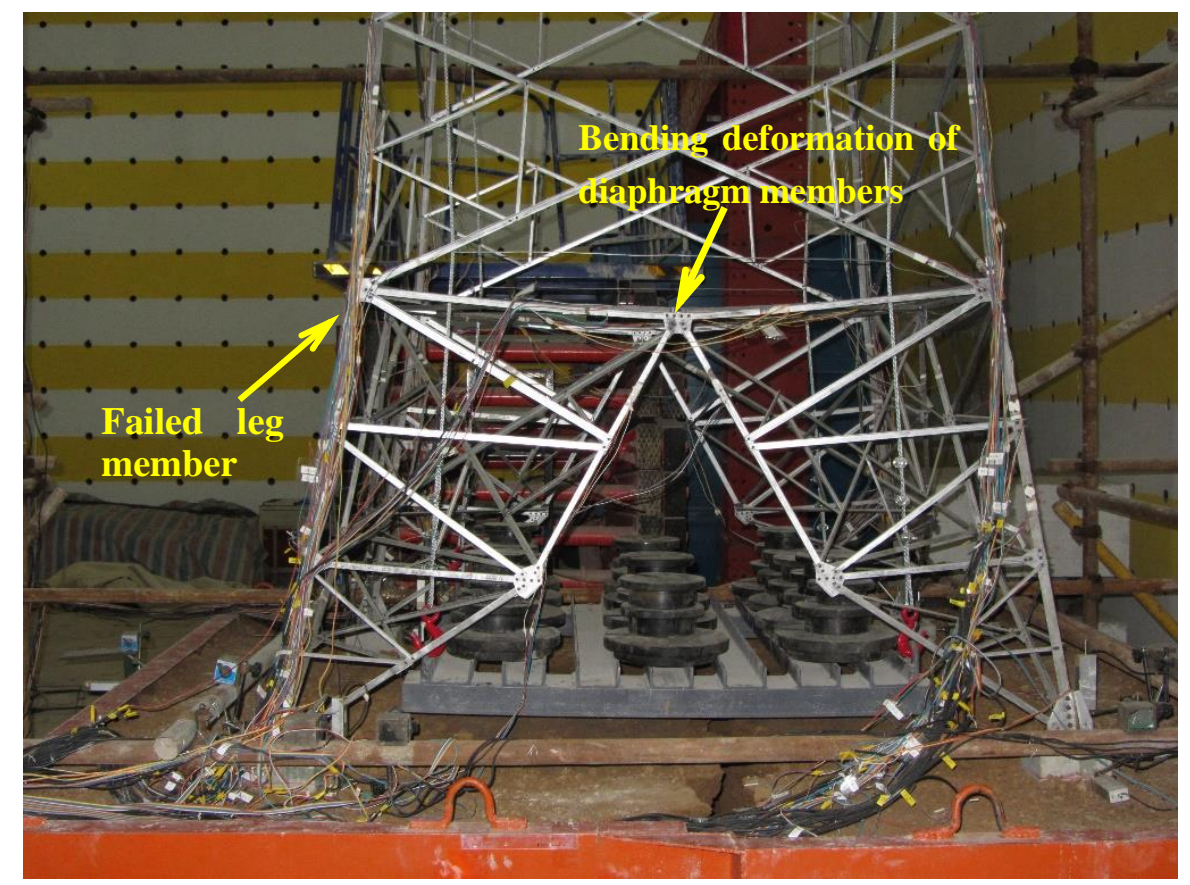

(a) Failure mode of the scaled tower model with isolated concrete foundation

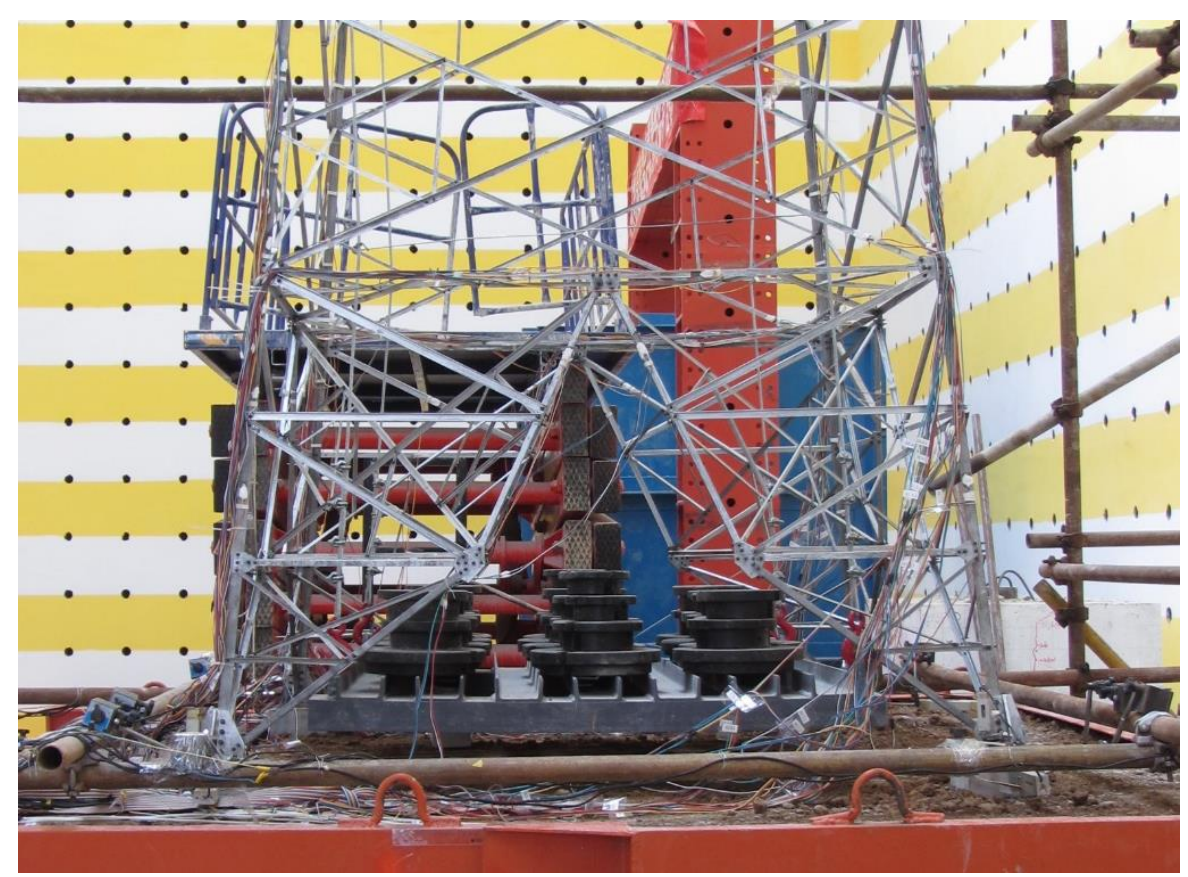

(b) Maximum deformed profile of the scaled tower model with hybrid slab foundation

Fig. 20 Comparison of failure mode of the scaled tower model with isolated foundations against the maximum deformed profile of the scaled tower with hybrid slab foundation. 


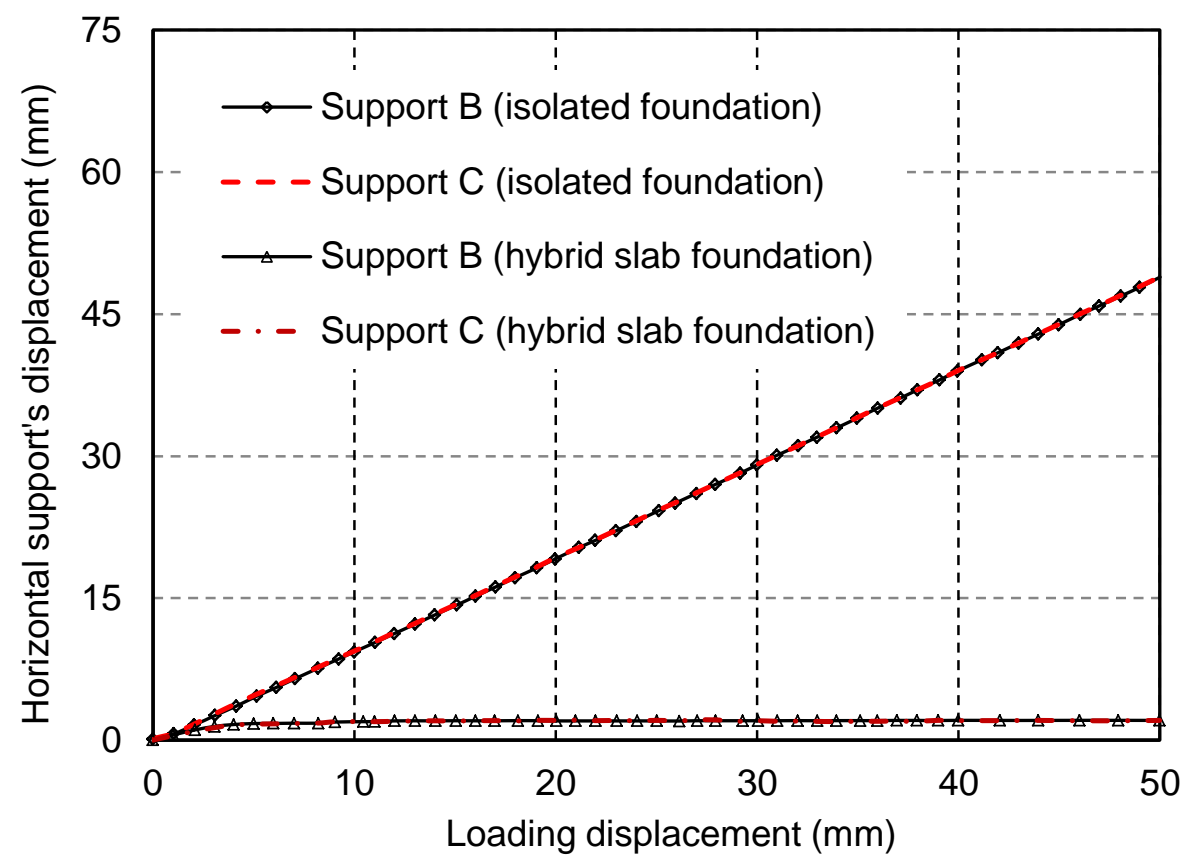

Fig. 21 The horizontal displacements of the supports with different foundations.

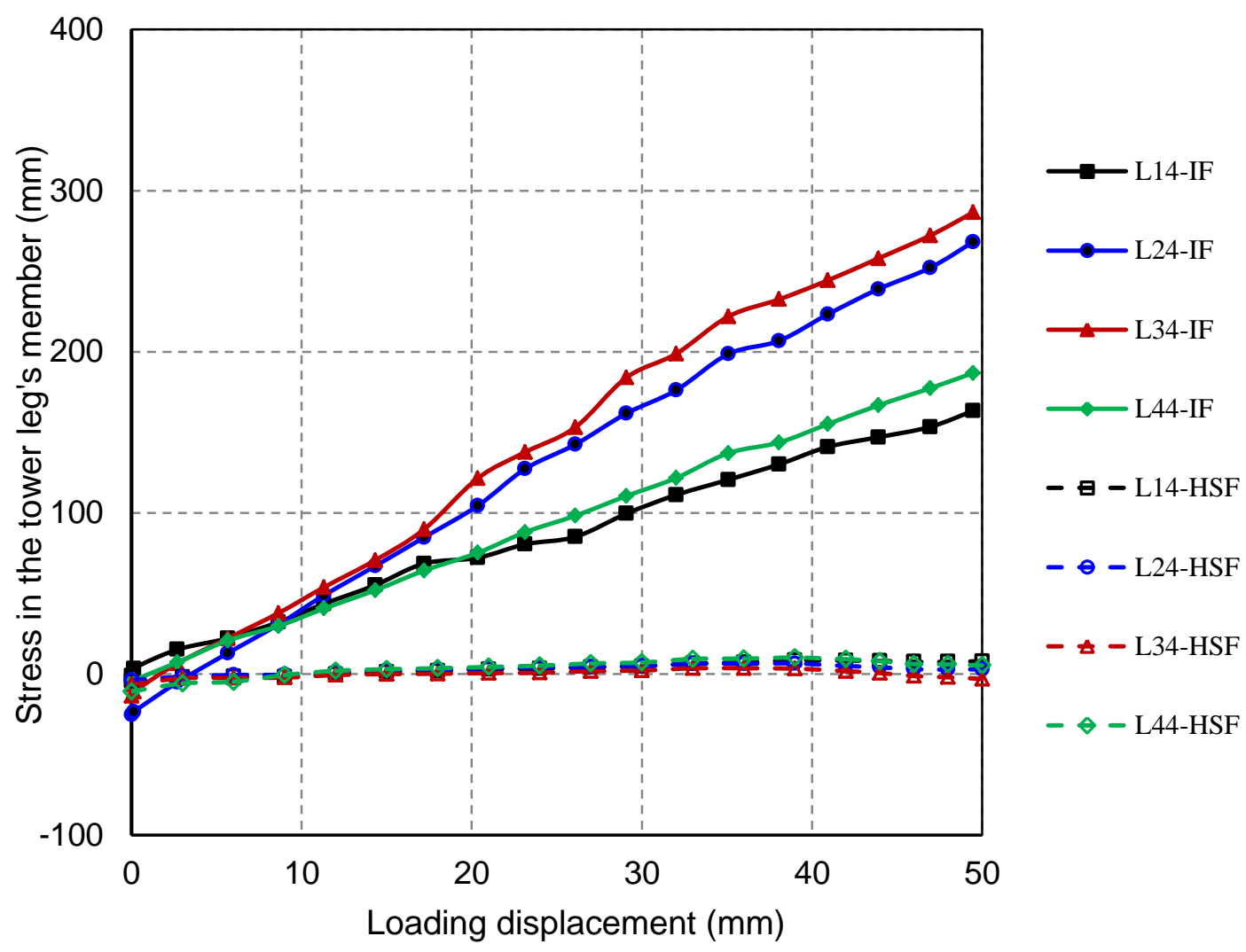

Fig. 22 Stresses within the tower legs' members with different type foundations ( $\mathrm{IF}=$ isolated foundation; $\mathrm{HSF}=$ hybrid slab foundation). 


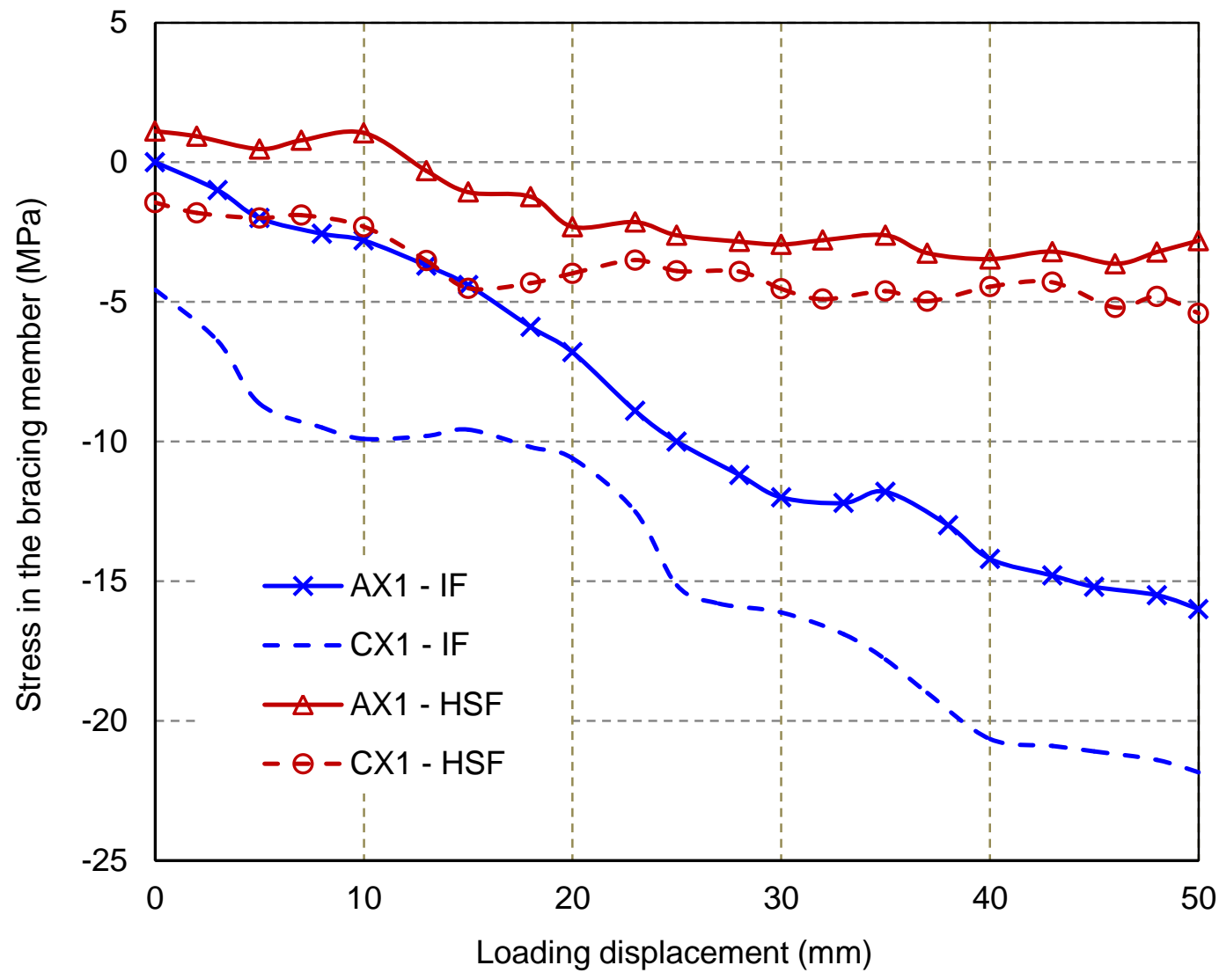

Fig. 23 The stresses in the first cross bracing members with different type foundations (IF $=$ isolated foundation; HSF $=$ hybrid slab foundation). 